\title{
ON THE ROLE OF PHONOLOGICAL SHORT-TERM MEMORY IN SENTENCE PROCESSING: ERP SINGLE CASE EVIDENCE ON MODALITY-SPECIFIC EFFECTS
}

\author{
Sonja A. Kotz and D. Yves von Cramon \\ Max Planck Institute for Human Cognitive and Brain Sciences and University of Leipzig, \\ Day Care Clinic of Cognitive Neurology, Germany \\ Angela D. Friederici \\ Max Planck Institute for Human Cognitive and Brain Sciences, Leipzig, Germany
}

\begin{abstract}
The present study explored a possible interaction between distinct language processes and components of phonological short-term memory (pSTM) in a patient with a pSTM profile. Event-related brain potentials (ERPs) were recorded while HG and age-matched controls engaged in auditory and visual sentence correctness tasks. Stimulus onset asynchrony ( $\mathrm{SOA}$ ) was varied in the visual modality. Controls showed an early anterior negativity followed by a P600 for syntactic violations and an N400 for semantic violations in the auditory and the short visual SOA condition. In the long visual SOA condition only a P600 and an N400 were observed. Across all tasks, HG displayed a comparable early anterior negativity and N400 pattern to controls. However, the P600 was replaced by a centro-parietal negativity $(500-800 \mathrm{~ms})$ that was followed by a very late positivity $(900-1300 \mathrm{~ms})$ in the visual modality, indicating that late syntactic processes are sensitive to SOA manipulation. This result implies that the cortical regions lesioned in HG may be part of a neural network that engages the pSTM system during "temporally variable" late syntactic processing in the visual modality. The combined results indicate that the pSTM system differentially impacts semantic and late syntactic processes.
\end{abstract}

\section{INTRODUCTION}

There is an ongoing debate about the nature of syntactic processing deficits in aphasic patients. Arguments are that either mechanisms subserving syntactic processing in both comprehension and production are affected (Caramazza, Berndt, Basili, \& Koller, 1981; Caramazza \& Zurif, 1976; Caramazza, Zurif, \& Gardner, 1978) or that reduced short-term memory capacities may influence syntactic processing (e.g., Caplan \& Waters, 1999; Caramazza, Basili, Koller, \& Berndt, 1981; Kolk \& Van Grunsven, 1985; Martin \& Feher, 1990; Saffran \& Martin, 1975). On the other hand, there have been reports that temporal dynamics of either access or integration of syntactic information during sentence comprehension are altered (Friederici, 1988; Haarmann \& Kolk,

Correspondence should be addressed to Sonja A. Kotz, Max Planck Institute for Human Cognitive and Brain Sciences, PO Box 500355, 04303 Leipzig, Germany (Email: kotz@cbs.mpg.de).

The authors would like to thank HG, who supported us without hesitation in this endeavour. Many thanks to Anja Hahne for providing the stimulus material of her dissertation to conduct this study. We are grateful to Ina Koch for running both the patient and the control experiments. 
1991; Prather, Zurif, Stern, \& Rosen, 1992). Similarly, temporal changes of the access or the integration of semantic information during sentence comprehension in both Broca's and Wernicke's aphasics have been proposed as critical features of the underlying deficit (Hagoort, 1993; Swaab, Brown, \& Hagoort, 1995). The current case study focuses on a direct comparison of the temporal dynamics of syntactic and semantic information processing (e.g., Friederici, 1988, 1995) during aphasic sentence comprehension in a patient with reduced $\mathrm{pSTM}$ capacities. Utilising ERPs in such a context allows an on-line monitoring of the computation of syntactic and semantic processes, thus providing direct evidence as to which critical factors (e.g., pSTM, timing) may play a role when specific language processes are altered.

Seminal work on syntactic processing deficits was reported by Caramazza and colleagues (Caramazza et al., 1978, 1981; Caramazza \& Zurif, 1976). In particular, some of the authors put forward that a syntactic impairment is confirmed when several tasks that require on-line analysis of syntactic processing are affected. Comparing different aphasic patients (Broca, Wernicke, and conduction aphasics) in expressive (story completion test, oral reading) and receptive tasks (sentence-picture matching, sentence anagram test) revealed that Broca's aphasics show selective deficits in both expressive and receptive tasks, while a conduction aphasic showed asyntactic comprehension, but no agrammatic speech, and a Wernicke's aphasic showed affected comprehension, but good production (Caramazza et al., 1981; Caramazza \& Zurif, 1976). The data suggest (1) that agrammatic speech and asyntactic comprehension do not have to cooccur (e.g., Berndt \& Caramazza, 1980) and (2) that asyntactic comprehension in Broca and conduction aphasia may not be based on the same underlying deficit (Caramazza et al., 1981).

The assumption that reduced pSTM capacities affect syntactic processes is based on theories of sentence processing which assume that sentence comprehension involves working memory space (e.g., Caplan, Vanier, \& Baker, 1986; Frazier \& Fodor, 1978; Just \& Carpenter, 1992; Kolk \& Van
Grunsven, 1985). However, research on aphasic sentence comprehension has critically debated the effects of memory span deficits on sentence comprehension (e.g., Caramazza et al., 1981; Martin \& Feher, 1990; Saffran \& Martin, 1975).

First, it has been argued that standard memory span tests may affect a different short-term memory (STM) to the one that may be active during sentence comprehension (e.g., Caplan et al., 1986; Kolk \& Van Grunsven, 1985; Martin \& Feher, 1990; McCarthy \& Warrington, 1987a, 1987b). Second, reports about patients with severely reduced memory spans and semantic deficits, but with excellent comprehension of syntactically complex sentences, support a possible differentiation of STM (e.g., for a review, see Caplan \& Waters, 1999; Martin, 1987; Martin \& Feher, 1990; Martin \& Romani, 1994). Last, Martin and Feher (1990) argued that STM deficits might be confounded with a sentence-processing deficit, since brain damage can reduce the speed of access and the parsing of sentence information. This implies that STM capacities might interact with speed of sentence processing. They proposed that, in order to examine the relative contribution of STM to sentence comprehension, factors such as the presentation mode ("limited" or "unlimited" as in variable presentation times of sentences) and the sentence complexity (length of sentences or structural complexity) need to be explored. Employing a "limited" and an "unlimited" presentation rate in both the auditory and visual modality, they tested fluent and nonfluent aphasics with left-hemisphere cerebrovascular lesions with two sentence types: token sentences (De Renzi \& Vignolo, 1962) and subject/object relative clauses. The difference between these sentence types is that token sentences reflect an increase of sentence length based on successive adding of content words, while relative clauses as a marker of sentence complexity might engage different parsing processes. The authors reported that reduced list memory spans affect the comprehension of token sentences at a limited but not an unlimited presentation rate and concluded that increasing sentence length, but not sentence complexity, is influenced by a STM deficits. 
Current pSTM models describe distinct subsystems such as the phonological store (e.g., Baddeley, 2003; Shallice \& Vallar, 1990) and the articulatory rehearsal process (e.g., Baddeley, 2003; Murray, 1968). Lesion studies (e.g., Shallice \& Vallar, 1990; Vallar, Di Betta, \& Silveri, 1997; Vallar \& Papagno, 1986) and PET studies with healthy subjects (e.g., Paulesu, Frith, \& Frackowiak, 1993; Paulesu, Passingham, Frackowiak, \& Frith, 1996) have supported a functional distinction of the pSTM, with the superamarginal gyrus as a main neuroanatomical correlate for phonological storage and the inferior part of Broca's area (BA 44/6) for articulatory rehearsal (Fiez, 1997; Paulesu et al., 1993).

To this end, two questions remain to be addressed. If pSTM plays a crucial role in sentence comprehension, under which circumstances do either the phonological store or the articulatory rehearsal process affect sentence comprehension? Furthermore, if aphasic sentence comprehension correlates with pSTM deficits one needs to discuss whether pSTM capacity has a differential effect on specific language processes.

Sentence processing models propose that the integration of syntactic and semantic information during sentence comprehension follows a particular temporal structure (Frazier \& Fodor, 1978). Friederici (1995) described that during the first stage, an initial first-pass parsing process assigns a primary syntactic structure based on word category information. During a second stage, lexicalsemantic integration takes place. In a third stage, second-pass parsing processes engage mapping procedures to integrate syntactic and lexico-semantic information such as thematic role assignment. The assumption underlying these two processes is that the first-pass processing is early, fast, and structuredriven (see, for alternative explanations, Frazier, 1987; Gorrell, 1995), while second-pass processing may involve late integrational processes that induce reanalysis if necessary (Hahne \& Friederici, 1999). A further implication of this model is that firstpass processes are susceptible to changes of temporal parameters of the language input. Slowed down access of primary syntactic information would render this early process inefficient while a temporarily modified late process could still be functional (Friederici, Hahne, \& Von Cramon, 1998; Friederici \& Kilborn, 1989).

Behavioural evidence from on-line studies of agrammatic sentence comprehension (Friederici, 1985) as well as syntactic priming studies with Broca's aphasics (Friederici \& Kilborn, 1989; Haarmann \& Kolk, 1994; Kilborn \& Friederici, 1994; Lukatela, Ocic, \& Shankweiler, 1991) indicate pathological temporal processing changes. The majority of studies report a slowed-down activation of on-line syntactic processing, which results in sentence comprehension problems. In line with this view, Haarmann and Kolk (1990, 1994) demonstrated that the performance of Broca's aphasics improved by increasing the interstimulus interval (ISI) between a syntactic prime and target. While an increase of computational time to process relevant information may improve late controlled processes in the performance of Broca's aphasics, the slowing down of activation would critically affect first-pass parsing processes, since these processes are normally fast (Friederici, 1995).

Temporal alterations of semantic processing have also been explored with aphasic patients. However, while the literature reports controversial automatic and controlled semantic priming effects in Broca and Wernicke aphasics (Goodglass \& Baker, 1976; Hagoort, 1993, 1997; Katz, 1988; Milberg \& Blumstein, 1981; Milberg, Blumstein, \& Dworetzky, 1987; Ostrin \& Tyler, 1993), there is very little evidence of temporal alterations of semantic information during sentence comprehension in aphasic patients (Friederici et al., 1998; Swaab, Brown, \& Hagoort, 1997) other than a few studies testing the resolution of lexical ambiguity in sentence context (Hagoort, 1990; Swaab et al., 1995).

Since the evidence on the temporal dynamics of aphasic sentence processing is inconclusive, some studies (Friederici, Hahne, \& Von Cramon, 1998; Friederici, Von Cramon, \& Kotz, 1999; Swaab et al., 1995, 1997) have explored aphasic sentence comprehension with ERPs, a method that allows the on-line monitoring of language processing millisecond by millisecond. Evidence from sentence comprehension studies with normal subjects indicates 
that there might be three different language-related components (e.g., Van Petten \& Kutas, 1991). Consistent with the parsing model discussed earlier (Frazier \& Fodor, 1978), there are reports that first-pass parsing processes correlate with an early anterior negativity elicited by word category violations (Friederici, Pfeifer, \& Hahne, 1993; Neville, Nicol, Barss, Forster, \& Garrett, 1991; however, see Gunter, Jackson, \& Mulder, 1997; Penke, Weyerts, Gross, Zander, Münte, \& Clahsen, 1997). In connected speech the component is elicited between 100 to $300 \mathrm{~ms}$ (Friederici et al., 1993) with a left lateralised or bilateral anterior distribution, while it is biphasic in the visual modality with an early left anterior negativity between 100 to $300 \mathrm{~ms}$ followed by a left-temporal negativity between 300 to $500 \mathrm{~ms}$ (Gunter, Friederici, \& Hahne, 1999). Second-pass parsing processes are reflected in a bilateral late centro-parietal positivity around $600 \mathrm{~ms}$ (P600) elicited by syntactically nonpreferred structures as well as syntactic violations in both modalities (Hagoort, Brown, \& Groothusen, 1993; Osterhout \& Holcomb, 1992). The early anterior negativity may reflect processes of initial syntactic structure building, while the P600 may correlate with syntactic reanalysis (see Friederici, 1998) or integration (Kaan, Harris, Gibson, \& Holcomb, 2000). Alternatively, the left anterior negativity (LAN) has been argued to reflect fluctuations in WM requirements during sentence comprehension (King \& Kutas, 1995; Kluender \& Kutas, 1993). Last, a centro-parietal negativity with a post-stimulus onset of $400 \mathrm{~ms}$ (N400) has been assimilated with lexico-semantic processes (e.g., Kutas \& Hillyard, 1983).

Friederici and colleagues (1998) used the abovedescribed model to investigate syntactic and semantic information processing during aphasic sentence comprehension. Patient WS, who suffered from an extended lesion restricted to the anterior part of the left hemisphere, displayed an N400, a P600, but no early anterior negativity. In contrast, patient GR, with a circumscribed lesion in the posterior part of the left hemisphere, showed an early anterior negativity, a delayed positivity (1200 ms), but no N400 component. The authors concluded that the left frontal areas might subserve the fast processes of initial structure building reflected in the early anterior negativity and that the left temporal areas support aspects of lexical semantic processing reflected in the N400 component. However, two studies that also investigated semantic information processing at the sentence level (Swaab et al., 1995, 1997) reported a general decrease in the N400 component with no group differences between Broca and Wernicke aphasics. ${ }^{1}$

\section{THE PRESENT STUDY}

The goal of the present study was to further explore a possible interaction between WM and distinct sentence processes (syntactic and semantic) by systematically exploring the temporal pattern of aphasic information processing with two factors: presentation rate (SOA) and presentation mode (modality) utilising ERPs (see also Starr \& Barrett, 1987, for a similar single case ERP approach in the nonlinguistic domain). The aim was to find out how the temporal adaptation of syntactic and semantic information processes correlates with memory span measures in an aphasic patient (hereafter referred to as $\mathrm{HG}$ ).

Exploring possible functional processing deficits, we set out to measure three language-related components in a sentence judgment task: the early anterior negativity, the $\mathrm{P} 600$, and the N400. Based on a previous study with aphasics using the same stimulus material (e.g., Friederici et al., 1998), we predicted that HG should display an early anterior negativity in the syntactic condition since the small lesion in the anterior part of the cortex did not include Broca's area (see Friederici, Kotz, Werheid, Hein, \& Von Cramon, 2003a; Friederici, Von

\footnotetext{
${ }^{1}$ Note, however, that in these studies no behavioural task was applied that would have allowed the analysis of correctly understood sentences from those that were not understood. The analyses were thus conducted on data averaged over correctly and incorrectly understood sentences.
}

\section{COGNITIVE NEUROPSYCHOLOGY, 2005, 22 (8)}


Cramon, \& Kotz, 1999), which has been identified as one of the neural sources of the early anterior negativity (in addition to a temporal source; see Friederici, Rueschemeyer, Hahne, \& Fiebach, 2003b; Friederici, Wang, Herrmann, Maess, \& Oertel, 2000). On the other hand, if the early anterior negativity reflects working memory related processes, HG should show an attenuation of the early anterior negativity due to a pSTM deficit. Second, if pSTM deficits generally correlate with sentence comprehension there should be some modulation of the late integrational processes reflected in the P600 component (Caplan \& Waters, 1999; Kotz \& Von Cramon, 1999) and the N400 (Friederici et al., 1998; Swaab et al., 1997). More specifically, it was assumed that the upkeep of information in the visual modality should be more problematic than in the auditory modality due to the word-by-word presentation. The pSTM deficit should be more obvious in the long SOA condition than in the short SOA as the global time to hold sentence information in pSTM was more extensive. Last, to control whether the attenuation of language-related ERP components is due to processing deficits, we also recorded nonlinguistic ERP components (P300) in an auditory and visual oddball paradigm. This paradigm allows to test for basic perceptual and nonlinguistic cognitive deficits such as attention. If the attenuation of an ERP component is due to a languagerelated processing deficit, the patient should show a normal ERP P300 pattern.

\section{Method}

\section{Age-matched controls}

Eight right-handed age- and gender-matched controls with no history of brain disease participated in the experiment. The mean age was 48 years with a range from 43 to 51 years.

\section{Patient history and description}

Patient HG is a 46-year-old right-handed male who suffered from an ischaemic stroke with lesions within the supply area of two cortical branches of the left middle cerebral artery
(MCA). Due to individual MCA branch occlusions an embolic mechanism seems likely. It should be noted that cerebral angiography visualised a filiform stenosis of the extracranial portion of the left internal carotid artery. A cardiogenic source of emboli could not be detected. The lesion sites were confirmed by (T1- and T2-weighted) MRI (Figure 1).

The 3D MR dataset revealed a small left frontal lesion area (presumably characterised by incomplete tissue necrosis) in the supply area of the prerolandic artery, damaging both a minor portion of the inferior precentral gyrus and the adjacent foot region of the second frontal convolution. The third frontal convolution, including

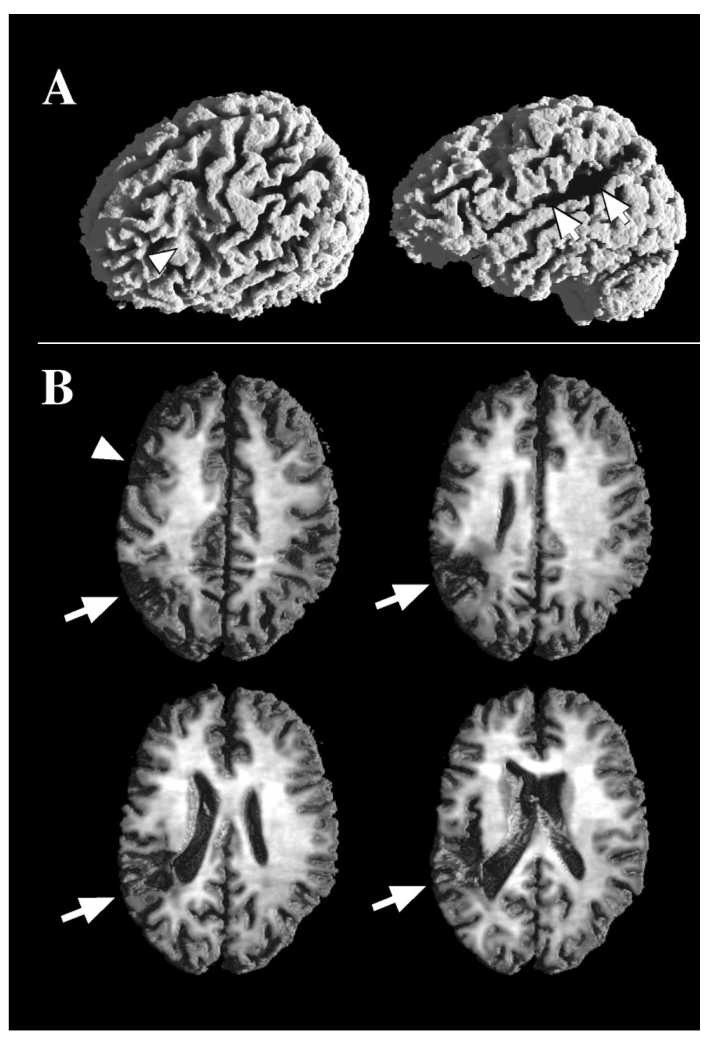

Figure 1. A: lateral view; B: axial slices. Patient $H G$ suffered a left-sided ischaemic stroke within the supply area of the prerolandic artery (arrow head) and the posterior parietal artery (arrows) of the left middle cerebral artery. For details see text. 
Broca's area appears completely spared. A considerably more extended and completely necrotic lesion marks the cortical and subcortical supply area of posterior insular branches and the posterior parietal artery. Within the lesion area lies the posterior insula (the long insular gyrus) and the supramarginal gyrus. The latter is damaged along the banks of the markedly widened posterior and ascending terminal ramus of the Sylvian fissure up to the intraparietal sulcus. The deep white matter compartment of the posterior parietal branch is also lesioned, with the trigone of the left lateral ventricle enlarged. Partial damage to the posterior planum temporale and the anterior angular gyrus cannot be excluded. Heschl's gyrus, however, seems preserved. In summary, according to the classification of Willmes and Poeck (1993), HG suffered from a small anterior and a large parietal lesion.

\section{Psychoacoustic and phonological evaluation}

Basic acoustic perception was evaluated with an audiogram and a test on monaural frequency detection. Both tests revealed that HG was well within the norm of age-matched controls.

In a second step, phonological analysis (see, for comparison, Vallar et al., 1997) was tested. HG was given a consonant discrimination task and asked whether two stop consonant-vowel (CV) syllables (/pa/, /ba/, /ta/, /ka/, /da/, and /ga/) presented one immediately after the other were identical $(\mathrm{pa}-\mathrm{pa})$ or different $(\mathrm{ba}-\mathrm{da})$. In total 10 training items (different from testing items) and 15 test items were presented auditorily. The task was to point either to the word "identical" or "different" printed on piece of paper that lay in front of the patient. HG scored 15 out of 15 , a result comparable to age-matched controls. Furthermore, repetition of auditorily presented sounds (/a:/, /o:/, /ö:/, /oi/, /t/, /p/, /k/, /sch/, /f/, and $/ \mathrm{ch} /$ ) and one-syllable words was also close to normal. The repetition of sounds resulted in 28 out of 30 points (a score of 3 per item indicates no deficit) and that of words in 26 out of 30 points. The repetition of 10 high-frequency foreign words (e.g., pilot, hepatitis, moderator) resulted in 25 out of 30 points. Reading of words was also unaffected. From these data it can be concluded that HG does not suffer from a phonological deficit (e.g., a deficit related to phonological analysis). On the other hand, the repetition, reading, and writing of one- and two-syllable pseudowords (adhering to the phonotactic rules of German) was strongly affected. For example, during repetition, HG scored 1 out of 10 (one-syllable pseudowords) and 2 out of 10 (two-syllable items), respectively. As the repetition of pseudowords involves the intermediate storage of phonological information independent of lexical representation, this result supports the idea that HG suffers from a phonological storage deficit.

\section{Speech and language evaluation}

The patient was classified as a nonfluent moderate Broca's aphasic according to a standard German aphasia test, the Aachener Aphasie Test (AAT; Huber, Poeck, Weniger, \& Willmes, 1983). The classification of Broca's aphasia was due to low scores on the subtests of naming and repetition of sentences in the AAT. Verbal production was nonfluent, effortful, and telegraphic; however, no motor speech organ paralysis was diagnosed. Auditory and visual comprehension scores of the AAT indicated relatively intact sentence comprehension (see also Miceli, Mazzucchi, Menn, \& Goodglass, 1983). The test scores of the relevant subtests are displayed in Table 1. Reading and writing capacities were only slightly affected. A diagnosis of conduction aphasia was eliminated as the verbal output of HG was nonfluent.

Since parts of the ERP/RT experiments involved the reading and the judgment of sentences, we tested the patient with a version of an experimental sentence-picture matching paradigm that involved different grammatical constructions (reversible and nonreversible structures) (Caramazza et al., 1981; Friederici \& Frazier, 1992). According to several authors (Caramazza et al., 1981; Linebarger, Schwartz, \& Saffran, 1983) different types of syntactic knowledge and tasks need to be compared in Broca's aphasics to

\section{COGNITIVE NEUROPSYCHOLOGY, 2005, 22 (8)}


Table 1. Patient history and comprehension scores ${ }^{a}$

\begin{tabular}{|c|c|c|c|c|c|c|c|c|}
\hline Classification & Age & Sex & Hand & $\begin{array}{c}\text { Onset to ERP } \\
\text { measure }\end{array}$ & $\begin{array}{c}\text { Token } \\
\text { Test }\end{array}$ & $\begin{array}{c}A A T \\
\text { compreh. score }\end{array}$ & $\begin{array}{l}\text { AAT auditory } \\
\text { compreh. score }\end{array}$ & $\begin{array}{l}\text { AAT visual } \\
\text { compreh. score }\end{array}$ \\
\hline Broca & 46 & $\mathrm{M}$ & $\mathrm{R}$ & $\begin{array}{c}\text { AUD } 12 \mathrm{~m} \\
\text { VIS (short) } 13 \mathrm{~m} \\
\text { VIS (long) } 14 \mathrm{~m}\end{array}$ & 3 & $110 / 120$ & $55 / 60$ & $56 / 60$ \\
\hline
\end{tabular}

${ }^{a}$ The severity of the language comprehension disorder is indicated by the number of mistakes in the Token Test: no/very mild disorder (0-6); light (7-23); severe (>40). In addition, the overall comprehension scores of the AAT average across the auditory and visual scores as well as separate auditory and visual scores are listed. The degree of the comprehension disorder is as follows: no/mild (107-120); light (90-106); severe (1-66).

define the nature of a syntactic comprehension deficit. Here, the sentence-picture matching task was administered twice. In the first session, 36 sentences were read to the patient one at a time at a normal speaking rate. After listening to a sentence, three pictures were presented. Pictures were black line drawings on white cards. One picture of the set always matched the corresponding sentence that was read out before, while two pictures were used as distracters (syntactic and lexical foils). Two weeks after the first session, the patient read the same sentences printed on a card and then selected the appropriate picture match from a set of three pictures. Listening comprehension was at $97 \%$ correct, while reading comprehension was at $92 \%$ correct. These results further supported HG's well-preserved comprehension for different grammatical sentence types when sentences were presented without time constraints. In addition, an adaptation of a sentence anagram task was administered. Each word of 15 sentences of various syntactic types (statement, question, tense) was printed individually on a card and presented in random order. HG was asked to arrange the sentences in the proper order. Rearrangement without time constraints resulted in 14 out of 15 correct sentences even though HG showed more insecurity in constructing questions than statements.

\section{Neuropsychological evaluation}

Auditory and visual digit span tests. In the auditory digit span $H G$ was instructed to immediately recall a list of digits after the examiner presented the digits $(1 / \mathrm{s})$. HG's recall in the forward span was clearly defective: 3.5 out of 12 items (normal range 6-10 out of 12). A similar picture emerged from the backward span: 2 out of 12 items (normal range: 6-9 out of 12). In addition, a nonverbal forward and backward visuospatial memory test was administered. Forward touching of a sequence of squares resulted in a reduced span: 3.5 out of 14 items (normal range: 7-10), while backward touching of the sequence resulted in 4 out of 12 items (normal range: 6-9). It thus appears that the nonverbal visual span was less affected than the auditory span. This result was further confirmed by good recall in the symbolic number test and average memory scores in middle and long-term memory recall for visual material (see Hawie-R, subtests of the WMS-R). In addition, the word length effect was investigated in the auditory modality using strings of two-, three- and foursyllable words (Vorländer, 1986). For immediate recall, HG initially did not show a word length effect (short words: 2; long words: 2; normal range: 4-6). However, in a second testing there was a trend for a word length effect (short words: 3; long words: 2) as well as for a phonological similarity effect (similar: 3; dissimilar: 4).

Lexical-semantic word span and syntactic category effects. Auditory short-term memory capacity was further measured with a serial recall task using different word types (see Hoffmann, 1996). Phonologically dissimilar, one-syllable concrete nouns, abstract nouns, and function words were tested auditorily at a rate of $1 \mathrm{~s}$ per word. For each word type there were lists of one, two, three, four, six, and eight items to recall. Ten trials were 
administered for each memory set. Two recall conditions were tested in two separate sessions: an immediate recall after each sequence of items was heard or a delayed recall after $9 \mathrm{~s}$. If there was no recall or the serial recall of five items was not ensured, the test was interrupted.

On average, HG retained 2.5 concrete and abstract nouns and 3 function words in the immediate recall condition (normal range across word categories: 5-7.5). The scores in the delayed recall conditions were exactly the same (normal range across categories: 5-6.5). The data indicate that the testing of nonphonological factors does not reveal a categorical span effect. Interestingly, though, HG showed no recency effect for either word category. A missing recency effect for word category spans has been linked to an output problem of the phonological store (see Vallar \& Papagno, 1986).

Adapted reading span test. In order to evaluate the auditory reading span of $\mathrm{HG}$ and the agematched controls, a German adaptation of the reading span test by Daneman and Carpenter (1980) was used (Steinhauer, 1995). However, the length of the sentences was reduced since aphasic patients often show articulatory difficulties (Hoffmann, 1996). Therefore, sentences only contained 4 one-syllable words with the final word of a sentence always being a noun. Subjects were instructed to read a sentence from a card and to indicate immediately when they had finished reading the sentence. For each level of difficulty, maximally 5 runs of two, three, or four items were administered. HG did not manage to recall more than one item. In comparison, age-matched controls recalled 2.5 items (range: $2-3.5$ ).

Attention. Tests evaluating the speed and accuracy of information processing revealed that $\mathrm{HG}$ showed comparable results to age-matched controls (tonic alertness: PR 62; phasic alertness: PR 38). A test on divided attention showed that HG was slowed down (PR 12), but did not make mistakes (Fimm \& Zimmermann, 1993).

In summary, given his lesions and the neuropsychological test results, HG appears to suffers from a phonological storage deficit, which is further supported by his low scores on sentence repetition and naming (see language evaluation).

\section{Materials and tasks}

Auditory oddball task. The auditory oddball task used a two-tone block. Subjects heard standard tones $(600 \mathrm{~Hz})$ with a probability of .8 and deviants $(660 \mathrm{~Hz})$ with a probability of .2 . The block contained a total of 500 auditory stimuli. All stimuli had a duration of $200 \mathrm{~ms}$ (including $10 \mathrm{~ms}$ rise and $40 \mathrm{~ms}$ fall time; $75 \mathrm{~dB}$ SPL) and were presented with a constant offset-to-onset interval of $600 \mathrm{~ms}$. A pre-stimulus baseline of $200 \mathrm{~ms}$ was used.

Visual oddball task. The material in the visual oddball task consisted of 300 differently shaped objects (circle, triangle, etc.). Objects were presented for $200 \mathrm{~ms}$ and the ISI was $1200 \mathrm{~ms}$. One quarter of the objects were easily discernible by an opening (round), while $75 \%$ were not. The task involved counting the objects with a round marker. Maximum response time was $2500 \mathrm{~ms}$. A pre-stimulus baseline of $200 \mathrm{~ms}$ was used.

ERP sentence judgment task. Two versions of the same experimental paradigm were used (for specifics, see Hahne \& Friederici, 1999). In the auditory version the subjects listened to sentences that were either correct or incorrect, while in the visual version the subjects read the same sentences presented one word at a time. Words in the visual modality were presented in the centre of a CRT screen. The sentences in the auditory version were spoken by a trained female speaker. After recording sentences on an analogue tape they were digitised $(20 \mathrm{kHz}, 12$-bit resolution). The language material consisted of 192 auditorily or visually presented sentences. Half of these sentences were correct and half incorrect ( $25 \%$ semantically incorrect and 25\% syntactically incorrect). Syntactic violations were realised as a word category error (e.g., Die Schwester wurde im __ gebadet./The sister was in the __ bathed. [literal translation]), while lexical-semantic violations were due to a selectional restriction violation (e.g., Das Haus 
wurde gebadet. The house was bathed). German phrase structure rules require that a preposition is followed by a noun phrase and not by a verb phrase that results in a word category violation. The syntactically and semantically incorrect passive constructions were matched with correct sentence structures (e.g., Die Schwester wurde gebadet./ The sister was bathed]; Die Schwester wurde im Teich gebadet/The sister was in the pond bathed [literal translation]), allowing the comparison of the same critical verb participles of regular German verb forms starting with the morpheme ge- (correct vs. incorrect) in the semantic and syntactic condition, respectively. To control for possible prosodic or other acoustic cues before the critical verb participle in the incorrect syntactic condition, the speaker initially produced a correct sentence with a noun before the verb participle. During the preparation of the auditory material, the noun was spliced out of the digitised speech signal using a speech-editing tool. To prevent splicing being influenced by coarticulation, only nouns for which the phonological transition from preposition to noun and from noun to verb was comparable were used. Two speech experts evaluated the quality of the speech signal by listening to the speech material and by visually checking the corresponding waveform for deviations due to splicing. Neither the experts nor the participants detected any acoustic oddities.

\section{Procedures}

Subjects sat in a comfortable chair located in a sound-attenuating chamber. They listened to the stimuli via loudspeakers or read the sentences one word at a time from a CRT screen. During the presentation of the sentence material, participants were instructed to fixate a small star in the middle of the CRT screen and to avoid blinks during the presence of the fixation star. The fixation marker appeared on the screen $500 \mathrm{~ms}$ prior to the beginning of the sentence presentation (approximately $1800 \mathrm{~ms}$ ) and remained visible until $3200 \mathrm{~ms}$ after sentence offset. Then a frowning face (incorrect answer) and a smiling face (correct answer) were presented on the screen to the left and the right of the centre for $2500 \mathrm{~ms}$. During the $2500 \mathrm{~ms}$ presentation of the faces on the screen participants had to judge whether a sentence was correct by pressing the button that matched the side with the smiling face on the computer screen or incorrect by pressing the button that matched the side with the frowning face. The next trial started after an ISI of $1000 \mathrm{~ms}$. Response accuracy, not speed, was emphasised in the delayed judgment task. The visual presentation followed the same pattern. For the short visual presentation an SOA of 500 (300/200) ms was used. Across a sentence this SOA approximated the auditory presentation of $1800 \mathrm{~ms}$ per sentence. For the long visual presentation the SOA was set at $1100 \mathrm{~ms}$, with a stimulus presentation time of $600 \mathrm{~ms}$ and an ISI of $500 \mathrm{~ms}$. ERP recording sessions took place with a delay of 4 weeks between each session. This procedure was followed to reduce potential repetition effects due to the repeated presentation of similar sentence types across the three recording sessions.

\section{ERP recordings}

The electroencephalogram (EEG) was recorded from 19 tin electrodes secured in an elastic cap (10-20 system). The specific locations were: Fz, Cz, Pz, F7, F3, ATL, BL, WL, P3, P7, O1, F8, F4, ATR, BR, WR, P4, P8, O2 (e.g., Sharbrough, 1991). Vertical as well as horizontal electrooculograms (EOGs) were recorded from electrodes placed above and below the right eye and the outer canthus of each eye. All recordings were referenced to the left mastoid. The right mastoid was passively recorded to allow re-referencing of the left and right mastoid to linked mastoids. Electrode impedance was kept below $5 \mathrm{k} \Omega$. The electrical signals were recorded continuously and amplified within a bandpass from DC to $40 \mathrm{~Hz}$. Signals were digitised with a sampling rate of $250 \mathrm{~Hz}$. ERPs were time-locked to the critical final word in each sentence type and recorded until $1500 \mathrm{~ms}$ post stimulus. The first $100 \mathrm{~ms}$ of the critical word were used as a baseline in both modalities (see Hahne \& Friederici, 1999; Osterhout \& Holcomb, 1992; Penke et al., 1997, for similar procedures). 


\section{Results}

\section{ERP auditory oddball}

Controls. ERP waveforms are displayed in Figure 2. Due to technical problems the auditory P300 was not recorded for two subjects. As can be seen in Figure 3, individual subject data are labeled as A3 to A8 and are displayed as a function of increasing age. The target P300 was visible at all electrode sites for all subjects. While largest at parietal electrode sites, the size of the effect decreased from central to frontal electrode-sites. Controls varied in the size of the effect, as can be seen in the individual subject data (Figure 3). After visual inspection of the waveform, the mean amplitude was measured in the time interval from 250 to $650 \mathrm{~ms}$. Two separate repeated measures analyses of variance (ANOVAs), one for midline sites and one for two laterals, including the factors Condition and Electrode site, were calculated. The Geisser-Greenhouse correction (Geisser \& Greenhouse, 1959) was applied to repeated measures with more than one degree of freedom in the numerator. The ANOVA of the midline sites $(\mathrm{Fz}, \mathrm{Cz}, \mathrm{Pz})$ did not reveal a significant main effect of Condition, $F=1.25$, but the Condition $\times$ Electrode site interaction was

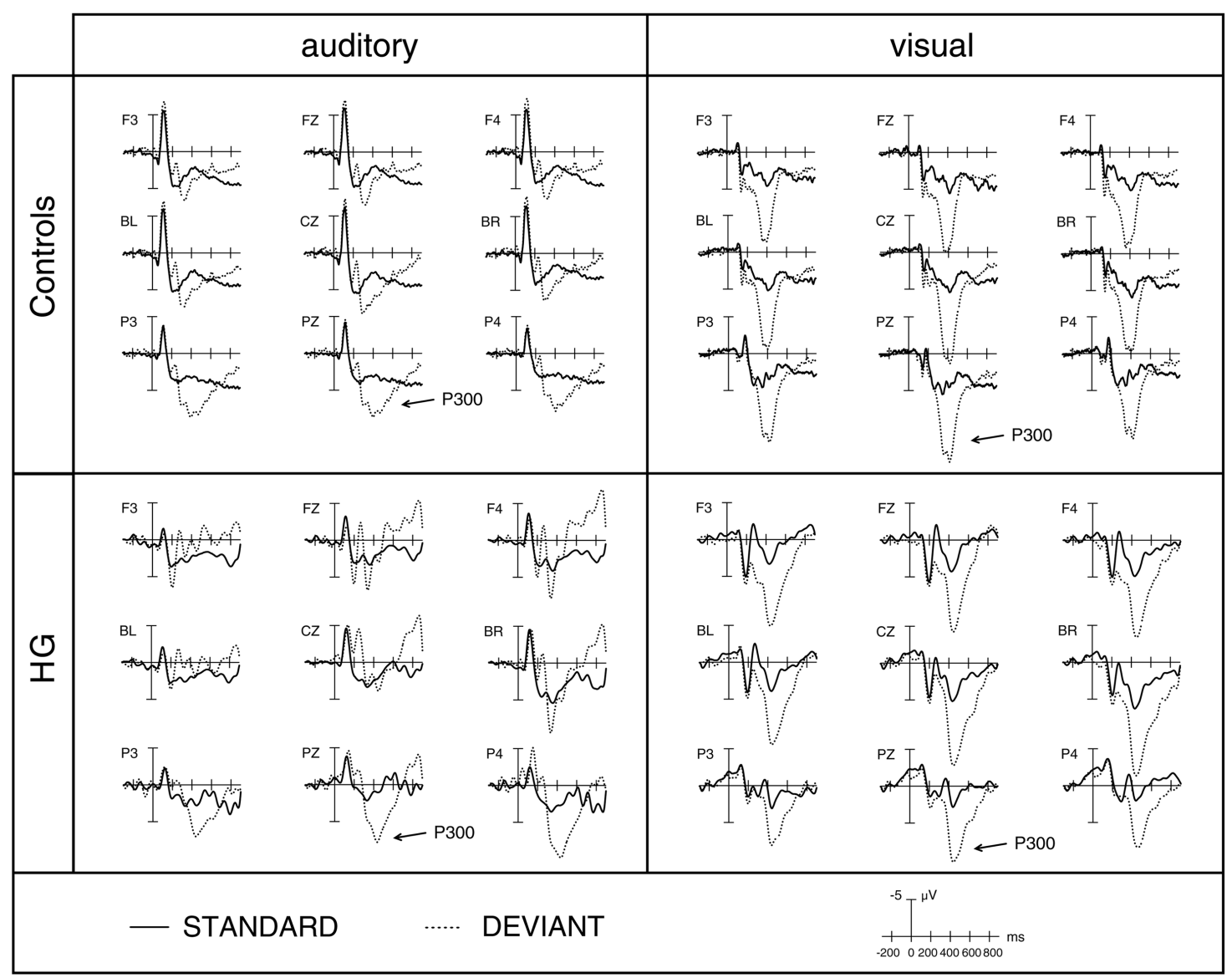

Figure 2. Displayed are the average ERPs for the auditory (left) and visual (right) P300 components at selected left/right frontoparietal electrode sites comparing the normal controls (top) with $H G$ (bottom). Waveforms are superimposed for the deviant (straight line) and standard (dotted line) tones and figures. The vertical lines indicate the critical onset of the target. A 200 ms pre-stimulus baseline was used. 


\section{Oddball individual subject data - P300}
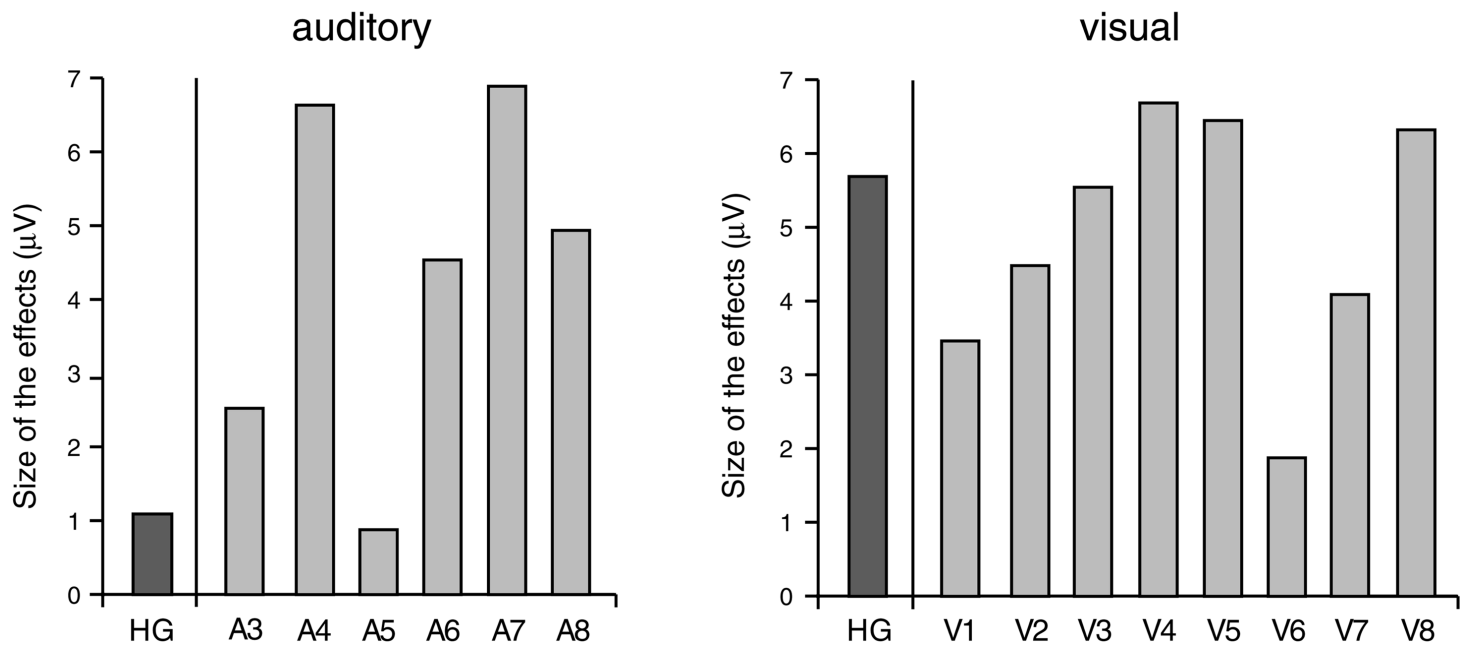

Figure 3. Graphical display of mean amplitude difference scores in $\mu V$ (deviant-standard), calculated across selected electrode sites and regions (anterior vs. posterior), of the P300 oddball effect comparing each individual control subject (lighter gray bars) with $H G$ (darker gray bar) in the auditory (left) and the visual (right) modality. Individual control subject data is labelled as A (auditory) plus a numeral (subject number) or V (visual) plus a numeral (subject number).

significant, $F(2,10)=9.25, p<.012$. The ANOVA including two sets of lateral sites (F3, BL, P3, F4, $\mathrm{BR}, \mathrm{P} 4)$ did not show a significant main effect of Condition, $F=1.14$, but the Condition $\times$ Electrode site interaction was significant, $F(2,10)=4.60$, $p<.040$. These results indicate that the P300 oddball effect is maximal at parietal electrode sites. Last, individual mean difference scores were calculated across the selected electrode sites and the time window of the ANOVA analysis. A confidence interval was then calculated with a Bonferroni adjustment to achieve a measure to compare normal and patient data. The confidence interval for controls was between 8.804 and $-0.004 \mu \mathrm{V}$.

$H G$. Since HG's data represent single case data we did not apply standard analyses of repeated measures of variance (ANOVAs; see also Friederici et al., 1998). Therefore, effects will only be described and data statistically evaluated by calculating confidence intervals for normal controls and HG. The target P300 was largest at parietal recording sites. The individual difference score of HG. (1.092) was within the confidence interval of the normal controls $(8.804,-0.004)$. If one assumes that the P300 reflects cognitive processes associated with the memory update of auditory stimulus classification (e.g., Mecklinger, Von Cramon, \& Matthes-von Cramon, 1998, for visual stimulus classification), this result suggests that these processes are not affected in HG.

\section{ERP visual oddball}

Controls. As can be seen in Figures 2 and 3 (individual subject data), controls (labelled as V1 to V8) display a P300 between 300 to $600 \mathrm{~ms}$ at frontoparietal electrode sites. It has been reported that the scalp distribution of the target P300 can become more frontal during healthy ageing (e.g., Friedman \& Simpson, 1994). Visual inspection of the current data supports this notion. A repeated measures ANOVA with Geisser-Greenhouse correction (Geisser \& Greenhouse, 1959) using the factors Condition, Electrode site, and Lateral were applied. The time window for mean 
Table 2. Accuracy rates comparing controls and $H G$ in the auditory, visual short $S O A$, and visual long SOA modality in the correct, syntactically incorrect, and semantically incorrect condition (top left to right)

\begin{tabular}{lccc}
\hline Participants & Correct & Syntactic & Semantic \\
\hline Controls & & & \\
Auditory & $99(100-94)$ & $96(100-83)$ & $97(100-90)$ \\
Visual short SOA & $99(100-98)$ & $99(100-97)$ & $99(100-96)$ \\
Visual long SOA & $99(100-97)$ & $100(100)$ & $97(100-85)$ \\
$H G$ & & & 92 \\
Auditory & 94 & 88 & 98 \\
Visual short SOA & 100 & 85 & 98 \\
Visual long SOA & 98 & 94 & \\
\hline
\end{tabular}

Note: Numbers in italics indicate HG's deficit in comparison to age-matched controls.

amplitude measurements at electrode-sites F3, $\mathrm{BL}, \mathrm{P} 3, \mathrm{Fz}, \mathrm{Cz}, \mathrm{Pz}, \mathrm{F} 4, \mathrm{BR}, \mathrm{P} 4$ was 300 to $600 \mathrm{~ms}$. The analysis showed a significant main effect of Condition, $F(1,7)=66.04, p<.000$, supporting the expected pattern of the P300 oddball effect in the controls. As for the auditory oddball task, a confidence interval (Bonferroni adjusted) was calculated for normal controls $(8.042-1.683)$.

$H G$. The scalp topography and latency of the visual P300 component displayed a target P300 that was largest and statistically significant at the expected parietal recording sites (see Figures 2 and 3). HG's individual difference score (5.691) was within the range of the controls. As argued for the auditory target P300 in the control group, the frontal distribution of the target P300 in HG could be the result of age (e.g., Friedman \& Simpson, 1994). Furthermore, the distribution of the target P300 could also indicate that the memory update for visual stimulus classification is not affected in HG.

\section{Auditory sentence judgment task}

Behavioural results-controls. A paired $t$-test (with adjusted degrees of freedom if necessary) was administered to the control data (Prather et al., 1992). Statistical results showed that subjects made similar amounts of errors judging grammatically incorrect or correct sentences, $t(7.1)=-0.841$, $p>.427$. The $t$-test comparing semantically correct and incorrect sentences displayed no differences, $t(8)=-1.463, p>.181$. Control subjects judged both types of incorrect (syntactic or semantic) and correct sentences with high accuracy.

Behavioural results - HG. The number of correct responses for $\mathrm{HG}$ and the controls for each modality (auditory or visually) and condition (correct, syntactically incorrect, semantically incorrect) are displayed in Table 2.

ERP results-controls. Waveforms for syntactically correct and incorrect trials are displayed in Figure 4. Individual subject data are presented in Figure 5. Approximately $7 \%$ of the trials across all critical conditions (48 trials per condition) were rejected due to eye blinks, horizontal eye movement, or amplifier blocking. Where necessary, normalisation procedures were applied to evaluate topographic differences in the ERP (McCarthy \& Wood, 1985). Closer inspection of the waveforms displayed no clear N1/P2 complex due to the continuous speech stream (see also Hahne \& Friederici, 1999). In the syntactic condition the controls showed a maximal early anterior negativity between 150 and $350 \mathrm{~ms}$, followed by a positive wave (P600) around 400 to $800 \mathrm{~ms}$ at centro-parietal electrode sites. Both the early anterior negativity and the P600 are comparable to previously reported ERP data that recorded brain potentials elicited to syntactic violations (e.g., Friederici et al., 1993). In the semantic violation condition the normal controls displayed a negativity with a peak latency at $400 \mathrm{~ms}$ post-stimulus onset at 
fronto-parietal sites with maximal activation at right-hemisphere electrode sites (see also Kutas \& Hillyard, 1983). For the sake of graphical coherence, all selected electrode sites were kept constant for the auditory and visual comparisons. After careful visual inspection and in comparison with previous analyses (see Friederici et al., 1998; Hahne \& Friederici, 1999), the following time-windows and regions of interest were selected for statistical analyses: early anterior negativity $(100 \ldots 300 \mathrm{~ms})$ : F7, ATL, F8, ATR, P600 (500 . 8 $800 \mathrm{~ms})$, late positivity (900 . . $1300 \mathrm{~ms})$, and N400 (300 . . $550 \mathrm{~ms})$ : left anterior: F7, F3, ATL, BL; right anterior: F8, F4, ATR, BR; left posterior: WL, P7, P3, O1; right posterior: WR, P8, P4, O2. A 100-ms poststimulus baseline was used for all conditions. While using a post-stimulus baseline does not necessarily follow standard procedures, it is a more conservative approach to test for differences in the current paradigm as the word types preceding the critical verb participle varied (prepositions vs. auxiliary verbs; see also Hahne \& Friederici, 1999; Osterhout \& Holcomb, 1992; Penke et al., 1997, for comparable procedures). It has been argued that prepositions behave differently during processing dependent on whether they are obligatory (closed class) or lexical (open class) in nature (Friederici, 1985). Since the prepositions used in the current experiment were lexical prepositions we preferred the post-onsetstimulus baseline.

Repeated measures ANOVAs with GeisserGreenhouse correction (Geisser \& Greenhouse, 1959) using the factors Condition and Electrode site were applied to the early anterior negativity. In the analyses of the late components (P600, late positivity, and N400) the factors Condition (correct/incorrect) AntPos (anterior/posterior) and Side (left/right) were included. The same procedures were used in both the visual short and long SOA control conditions.

The ANOVA for the early anterior negativity showed a significant effect of Condition, $F(1$, $7)=6.12, p<.042$. The interaction of Condition $X$ Electrode site was not significant, $F(3,21)=1.55$, $p>.251$. The ANOVA for the P600 component did not result in a significant main effect of Condition, $F(1,7)=3.53, p<.102$, but a main effect of AntPos, $F(1,7)=44.41, p<.000$, and a significant interaction of Condition $\times$ AntPos, $F(1,7)=6.76, p>.035$. While the $\mathrm{P} 600$ was not significant at anterior electrode sites, $F<1$, there was a main effect at posterior electrode sites, $F(1,7)=8.72, p<.021$. No other main effect nor interaction can be reported, all $F<1$. These results confirm the visual observation that the control group displayed a bilateral early anterior negativity and a P600 that was enhanced at posterior electrode sites. Analyses of the late positivity did not reveal a main effect of Condition, $F=1.21$. However, there was a main effect of AntPos, $F(1$, $7)=39.61, p<.000$, and a significant interaction of Condition $\times$ Side, $F(1,7)=7.86, p<.026$. No other main effect or interaction was significant, $F<1$. While it appears that the very late positivity is more enhanced at right-than left-hemisphere electrode sites, separate statistical evaluations of the left and the right hemisphere revealed a condition effect for both hemispheres.

The visual detection of the N400 component in the waveforms was confirmed by a significant main effect of Condition, $F(1,7)=34.70, p<.000$, AntPos, $F(1,7)=5.61, p<.0497$, a significant interaction of Condition $\times$ Side, $F(1,7)=14.34$, $p<.006$, and a significant three-way interaction of Condition $\times$ Side $\times$ AntPos, $F(1,7)=14.41$, $p<.006$. No other main effect nor interaction was significant, $F<1$. Separate analyses of side revealed a significant main effect of condition in both hemispheres: left, $F(1,7)=16.55, p<.004$; right, $F(1,7)=50.97, p<.000$, but no distributional differences across the scalp sites, $F<1$. The current results indicate that the N400 effect is distributed across all scalp sites.

Confidence intervals - controls. In order to ensure a statistically meaningful comparison of the ERP results between the normal controls and $\mathrm{HG}$, we calculated confidence intervals for each ERP component under investigation. We included anterior electrode sites for the early anterior negativity (F7, ATL; F8, ATR) as well as an anterior set of electrodes (F7, F3, ATL, BL, F8, F4, ATR, BR) and a posterior set of electrodes (WL, P7, P3, O1, WR, $\mathrm{P} 8, \mathrm{P} 4, \mathrm{O} 2)$ for the $\mathrm{P} 600$, the very late positivity, 
and the N400. The same time windows as in the ANOVAs for controls were used. After measuring the individual difference scores for each component $(\mu \mathrm{V})$ across the selected electrodes, we took additional steps to compare waveform deflections at anterior versus posterior electrode sites for the P600, the late positivity, and the N400 by calculating an index difference score. This was realised by subtracting difference scores for anterior sites from posterior sites for the late components. This additional step was taken to account for potential topographic differences when comparing the normal controls and HG. With the individual index scores we calculated confidence intervals for each component across controls. HG's index score for each of the late components and the individual score for the early anterior negativity was then compared to the respective confidence intervals of the normal controls. The $\alpha$-level was Bonferroni adjusted $(p<.03)$. This measure allowed to evaluate whether HG's scores lay within the normal distribution (as set by the control group) for each ERP component of interest (see Table 3 for results). This procedure was applied to all of the following analyses.

ERP results-HG. As has been reported above, HG's data represent single case data. In order to increase the signal-to-noise ratio in a single case as compared to group data, data were collected in two sessions and an eye artifact control measure developed at the MPI Leipzig (Pfeifer, Novagk, \& Maeß, 1995) was applied. As can be seen in Figure 4, due to the continuous speech stream no clear N1 and $\mathrm{P} 2$ components are visible in the waveforms. Closer inspection of the critical frontal electrode sites revealed an early anterior negativity. HG's difference score for the early anterior negativity was within the confidence interval of normal controls (see Table 3). The P600 with its maximal distribution at centro-parietal electrode sites was shifted to fronto-central sites. By visual inspection the late positivity was not comparable to that of the controls (but see confidence intervals, Table 3). An attenuated N400 between 300 and $550 \mathrm{~ms}$ followed by a positivity with a mean latency from 600 to $1200 \mathrm{~ms}$ were visible at frontal and midline electrode sites in the semantic condition. The N400 lay within the range of the confidence interval for the controls.

\section{Visual short SOA sentence judgment task}

Behavioural results-controls. A paired t-test was administered to the visual short SOA control data (Prather et al., 1992). In both the syntactic and semantic condition, controls displayed a fairly homogenous result of highly accurate sentence judgment. The paired $t$-tests comparing correct and incorrect responses in the syntactic condition, $t(14)=0.291, p>.774$, and in the semantic condition, $t(9.4)=-0.216, p>.833$,

Table 3. Summary of confidence interval values in $\mu V$ (Bonferroni adjusted) for each component and each modality, comparing controls and $H G$

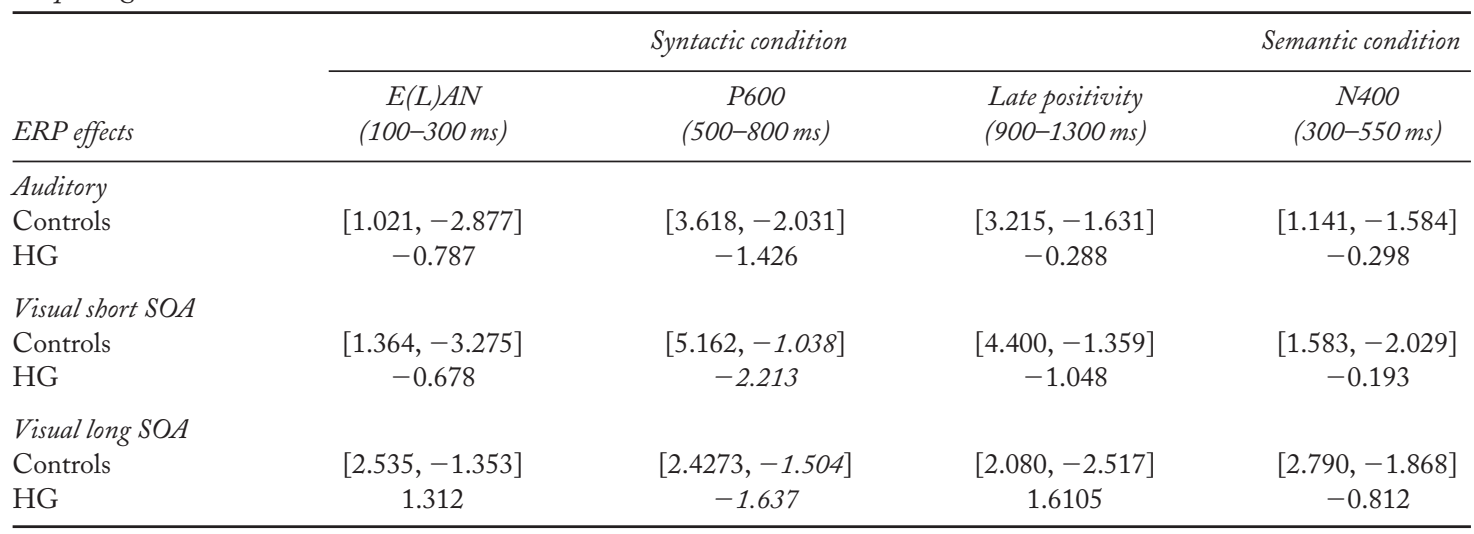

Note: Numbers in italics for the syntactic condition (P600) for HG indicate his deficit relative to age-matched controls. 


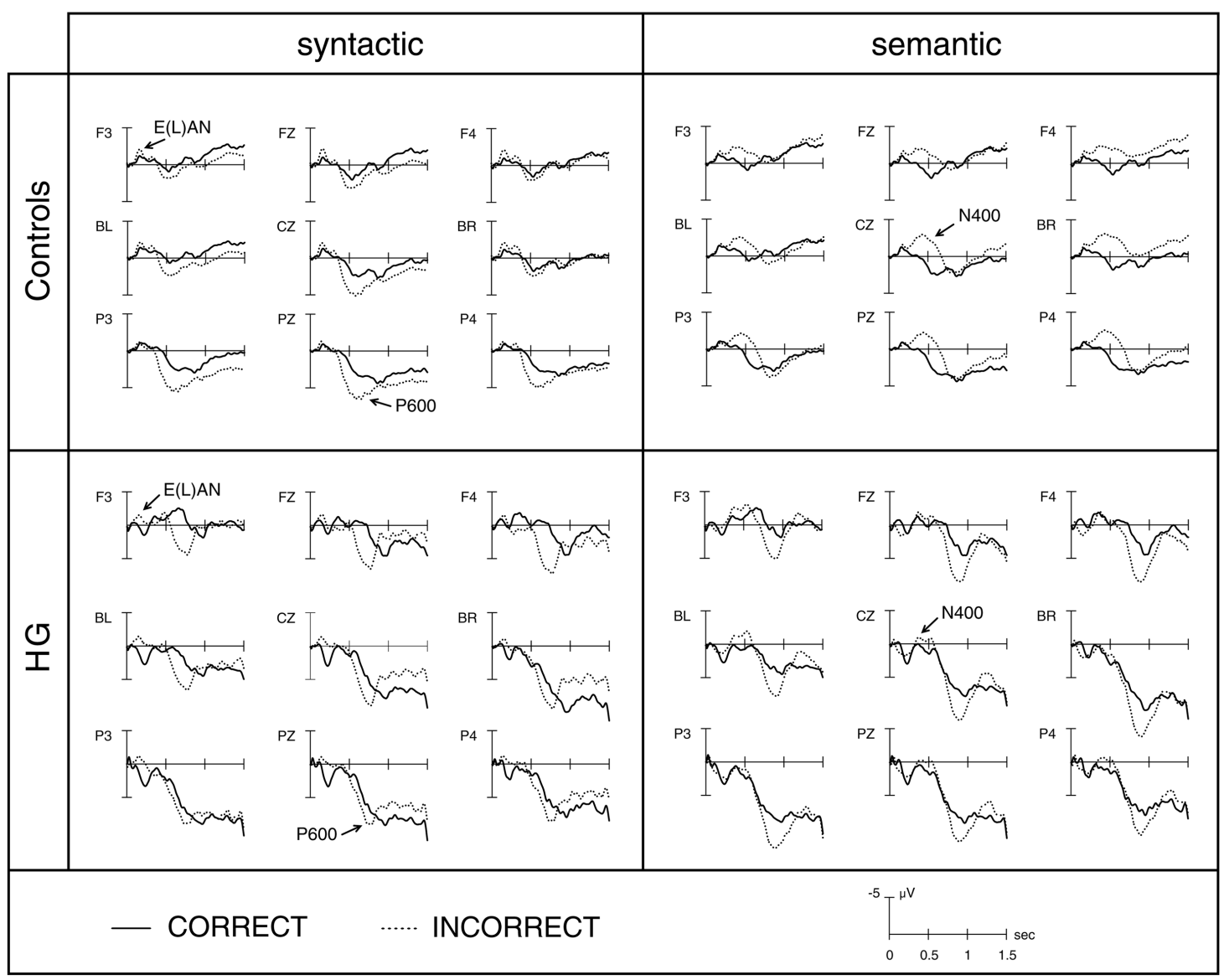

Figure 4. Displayed are the average ERPs for the $E(L) A N$ (abbreviation for early anterior negativity), P600, and N400 components at selected left/right frontoparietal electrode sites in the auditory modality. The waveforms are displayed for the syntactic (left) and semantic (right) condition comparing the controls (top) with HG (bottom). Waveforms are superimposed for the correct (straight line) and the incorrect (dotted line) conditions. The vertical lines indicate the onset of the critical word. The first 100 ms post-stimulus onset were used as a baseline.

did not reveal any significant differences. Control subjects judged both types of incorrect sentences and correct sentences at a high percentage correct (see Table 2).

Behavioural results- $H G$. The number of correct responses and conditions (correct, syntactically incorrect, semantically incorrect) for HG are displayed in Table 2.

ERP results - controls. Grand average waveforms of ERPs in the syntactic and semantic condition are shown in Figure 6. Approximately $8 \%$ of the trials across all critical conditions were rejected due to eye blinks, horizontal eye movement, or amplifier blocking. A broadly distributed N1 $(\sim 100 \mathrm{~ms})$ is followed by a P2 ( 200 ms). After these early components there is a bilateral early anterior negativity starting at 150 to $250 \mathrm{~ms}$ with a maximal activity at frontal and anterior electrode sites. This component is followed by a late bilateral centro-parietal positivity between 500 and $800 \mathrm{~ms}$ The succession of the early sensory components is comparable in the semantic and the syntactic 


\section{Individual subject data - auditory}
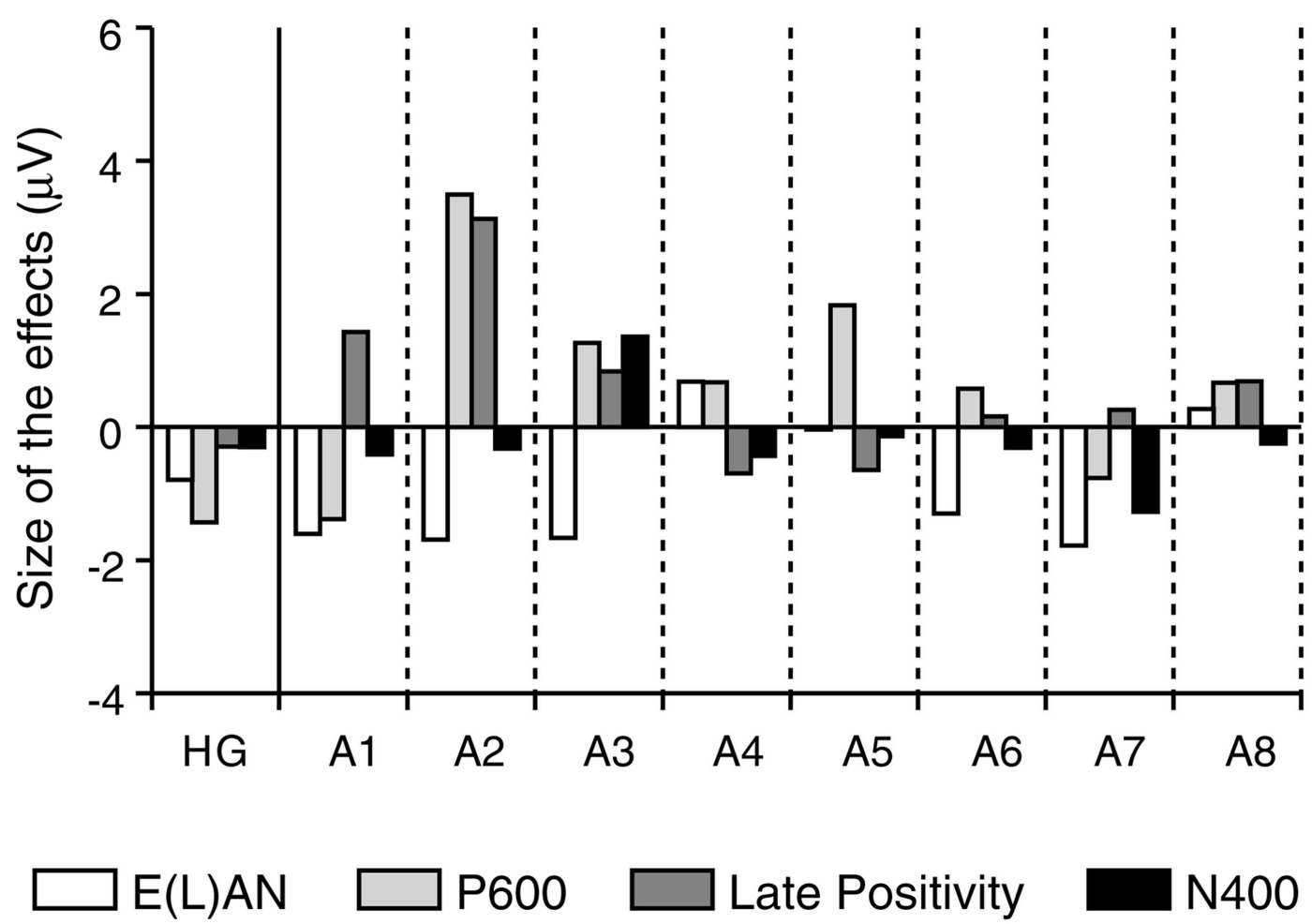

Figure 5. Graphical display of mean amplitude difference scores in $\mu V$ (incorrect-correct), calculated across selected electrode sites and regions (anterior vs. posterior), of the $E(L) A N$ (white bars), P600 (lighter gray bars), late positivity (darker gray bars), and $\mathrm{N} 400$ (black bars) effects comparing each individual control subject (right) with $\mathrm{HG}$ (left) in the auditory modality. Individual control subject data is labelled as A (auditory) plus a numeral (subject number).

condition. A negative effect between 300 and $550 \mathrm{~ms}$ post-stimulus-onset is visible at bilateral fronto-parietal electrode sites with an enhancement at fronto-central right electrode sites. In the syntactic condition, ERP waveforms to correct items were quantified at F3, F4, BL, BR with a latency window of 150 to $250 \mathrm{~ms}$ (early anterior negativity). All late components were quantified within the same regions and time windows and factors as in the auditory modality. Individual subject data are presented in Figure 7.

The repeated measures ANOVA in the syntactic condition for the early anterior negativity showed a significant trend for Condition, $F(1,7)=4.80$, $p<.064$, but no significant interaction of Condition $\times$ Electrode site, $F=0.31$. The analysis of the P600 component revealed no significant main effect of Condition, $F=1.31$, but a significant interaction of Condition $\times$ Side, $F(1,7)=12.49$, $p>.009$, and a three-way interaction between Condition $\times$ Side $\times$ AntPos, $F(1,7)=15.81$, $p>.005$. Separate analyses by side revealed no main effect of Condition, $F<1$, but a significant trend for interaction of Condition $\times$ AntPos at lefthemisphere electrode sites, $F(1,7)=3.60, p>.095$. A similar picture emerged for the right hemisphere. 


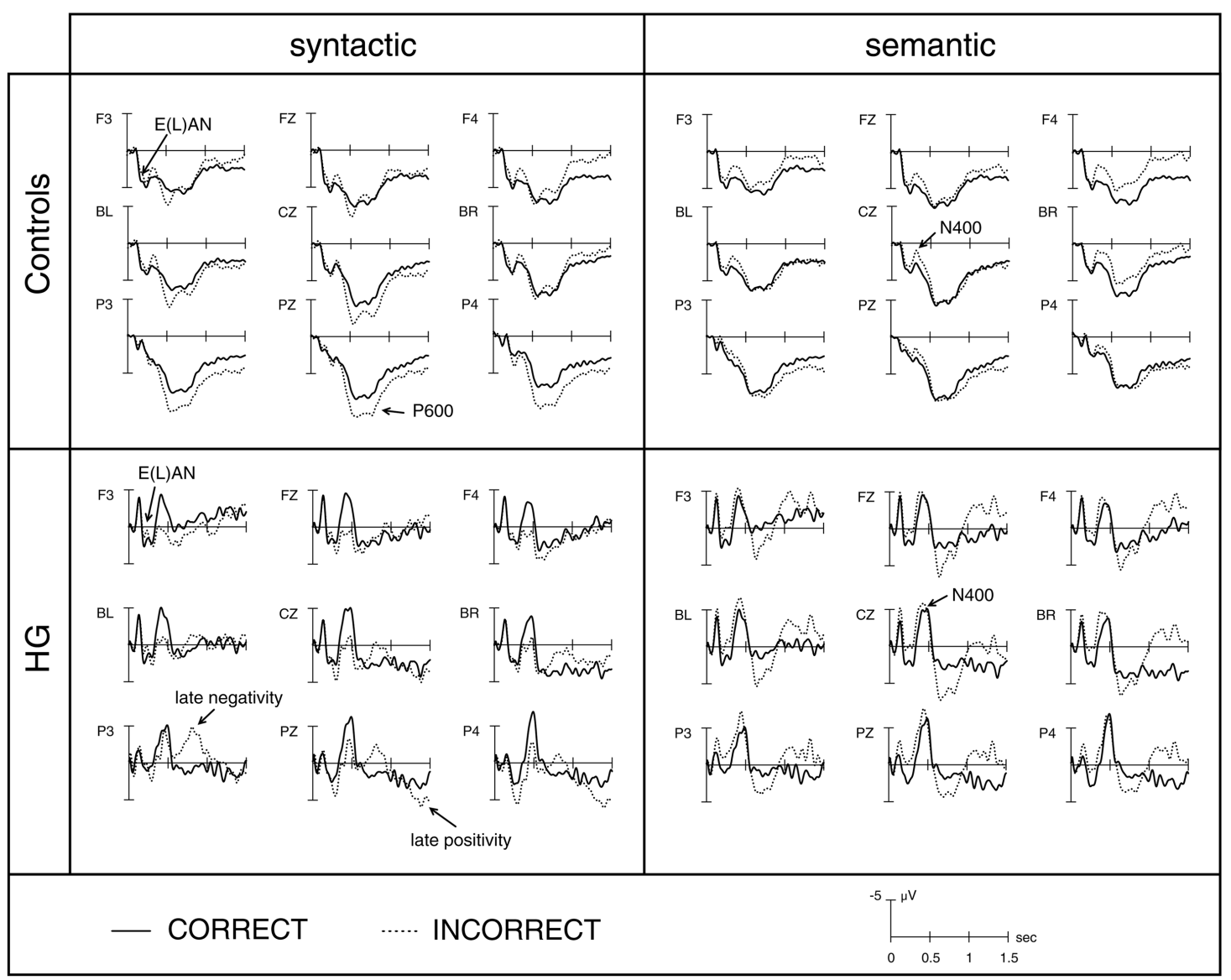

Figure 6. Displayed are the average ERPs for the $E(L) A N, P 600$, late positivity, and N400 components at selected left/right frontoparietal electrode sites in the visual short SOA modality. The waveforms are displayed for the syntactic (left) and semantic (right) condition comparing the controls (top) with $H G$ (bottom). Waveforms are superimposed for the correct (straight line) and the incorrect (dotted line) conditions. The vertical lines indicate the onset of the critical word. The first 100 ms post-stimulus onset were used as a baseline.

While there was no main effect for condition, the interaction between Condition $\times$ AntPos was significant, $F(1,7)=5.05, p<.050$. It became apparent that the $\mathrm{P} 600$ was maximally activated at right posterior electrode sites, $F(1,7)=6.80, p<.035$. No other main effect nor interaction was significant, $F<1$. The result of the early anterior negativity, while tentative, can be compared to data on the visual early anterior negativity (Gunter et al., 1999). In this study it was shown that the presence of an early anterior negativity in the time domain of 100-250 ms was dependent on the visual contrast of the input: It was present only when visual contrast was high, but delayed when visual contrast was low.

The analyses of the P600 confirm a maximal distribution of the component over posterior right-hemisphere electrode sites. Analyses of the late positivity in the early visual SOA condition revealed a comparable pattern to the $\mathrm{P} 600$. While there was no main effect of Condition, $F=0.38$, there was a significant interaction between the factors Condition $\times$ Side, $F(1,7)=6.30, p<.040$, and the factors Condition $\times$ Side $\times$ AntPos, $F(1$, $7)=7.69, p<.027$. The statistical analysis of the 

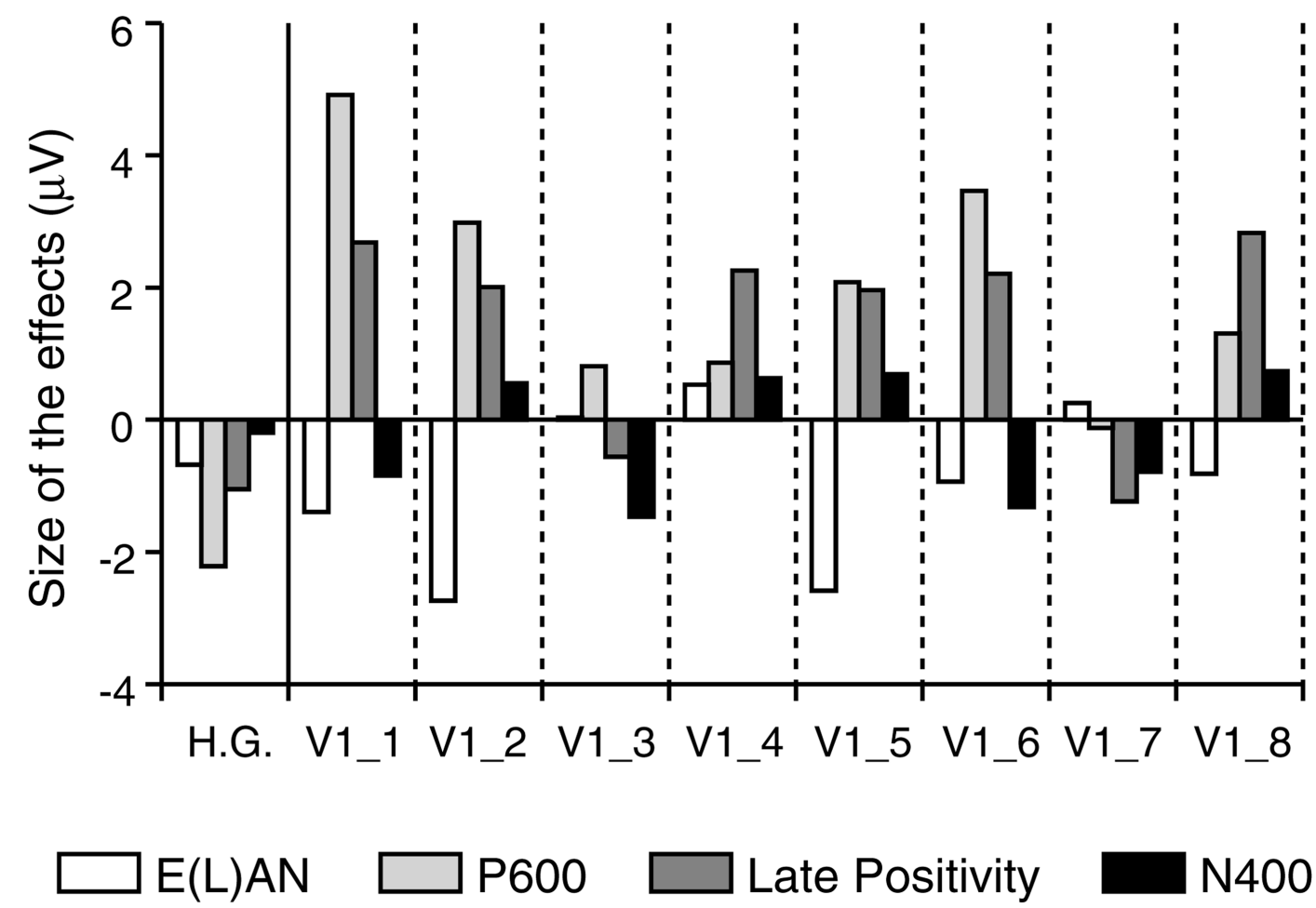

Figure 7. Graphical display of mean amplitude difference scores in $\mu V$ (incorrect-correct), calculated across selected electrode sites and regions (anterior vs. posterior), of the E(L)AN (white bars), P600 (lighter gray bars), late positivity (darker gray bars), and $\mathrm{N} 400$ (black bars) effects comparing each individual control subject (right) with HG (left) in the visual short modality. Individual control subject data is labelled as V1 (visual short) plus a numeral (subject number).

N400 revealed a significant main effect of Condition, $F(1,7)=5.93, p<.045$. No other main effect nor interaction was significant (all $F<1)$. The results confirm an N400 effect at all electrode sites.

ERP results - HG. Visual waveforms are displayed in Figure 6 for the syntactic and semantic conditions. As in the auditory version, eye artifacts were corrected in all of the visual conditions (Pfeifer et al., 1995). In the syntactic condition, there was a sharply peaked N1/ P2 complex at fronto-central sites, and a more reduced P1/N1 complex at posterior sites. The initial sensory component complex was followed by an early anterior negativity. The difference score for the early anterior negativity was within the confidence interval of the normal controls. The early negativity was followed by a second negativity (between 300 and $500 \mathrm{~ms}$, larger for correct than incorrect trials). In the time frame of the P600 (500-800 ms in the controls) a third negativity was visible (negative amplitude for incorrect trials larger that correct trials) at centro-parietal sites. This last negativity clearly was outside of the confidence interval for the P600 in the normal controls. Finally, a late positivity between 900 to $1300 \mathrm{~ms}$ was displayed. Calculations of the confidence interval for controls and HG confirmed that this delayed positivity was comparable. Visual inspection of the waveforms in the semantic condition indicated a negativity with a peak latency at $400 \mathrm{~ms}$, followed by a positivity between 600 and $900 \mathrm{~ms}$ at fronto-parietal left and midline sites. The N400 was within the normal distribution of the control group. While the scores for the early 


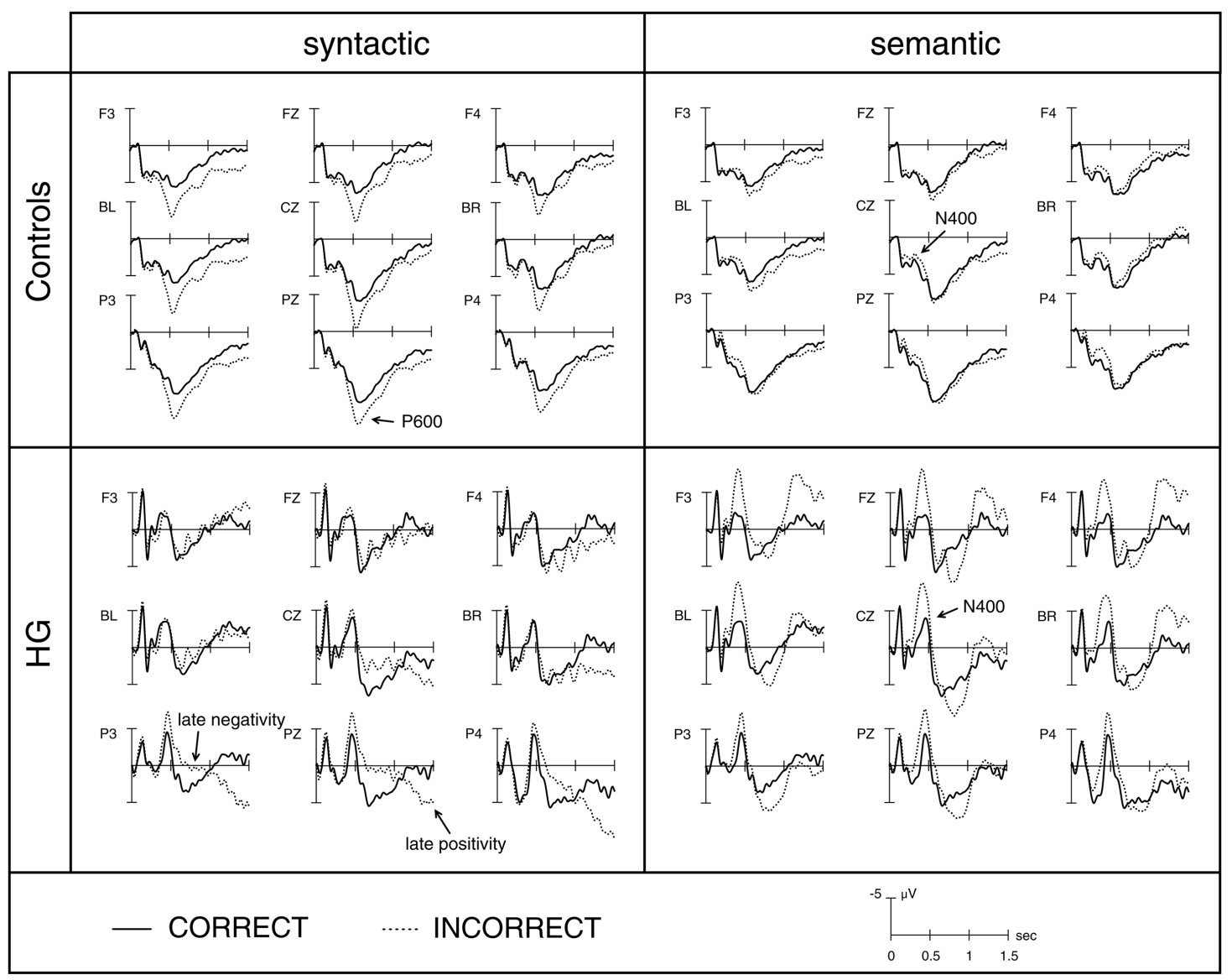

Figure 8. Displayed are the average ERPs for the $E(L) A N, P 600$, late positivity, and N400 components at selected left/right frontoparietal electrode sites in the visual long SOA modality. The waveforms are displayed for the syntactic (left) and semantic (right) condition comparing the controls (top) with HG (bottom). Waveforms are superimposed for the correct (straight line) and the incorrect (dotted line) conditions. The vertical lines indicate the onset of the critical word. The first 100 ms post-stimulus onset were used as a baseline.

anterior negativity and the N400 seem to be at the lower end of the confidence interval, the activation of the syntax-related $\mathrm{P} 600$ in the visual modality is absent. Taking together HG's behavioural and ERP results, it appears that late syntactic processes in the short SOA condition are modulated in the visual processing domain.

\section{Visual long SOA sentence judgment task}

Behavioural results-controls. A paired $t$-test was administered to the visual long SOA control data (Prather et al., 1992). The paired $t$-test comparing correct and incorrect responses in the syntactic condition, $t(14)=-1.4980, p>.156$, revealed that subjects judged both syntactically correct and incorrect sentences to be highly correct. There were no significant differences between semantically correct and incorrect sentences, $t(7.2)=-1.030, p>.336$.

Behavioural results- $H G$. The number of correct responses for each condition for HG are displayed in Table 2. 

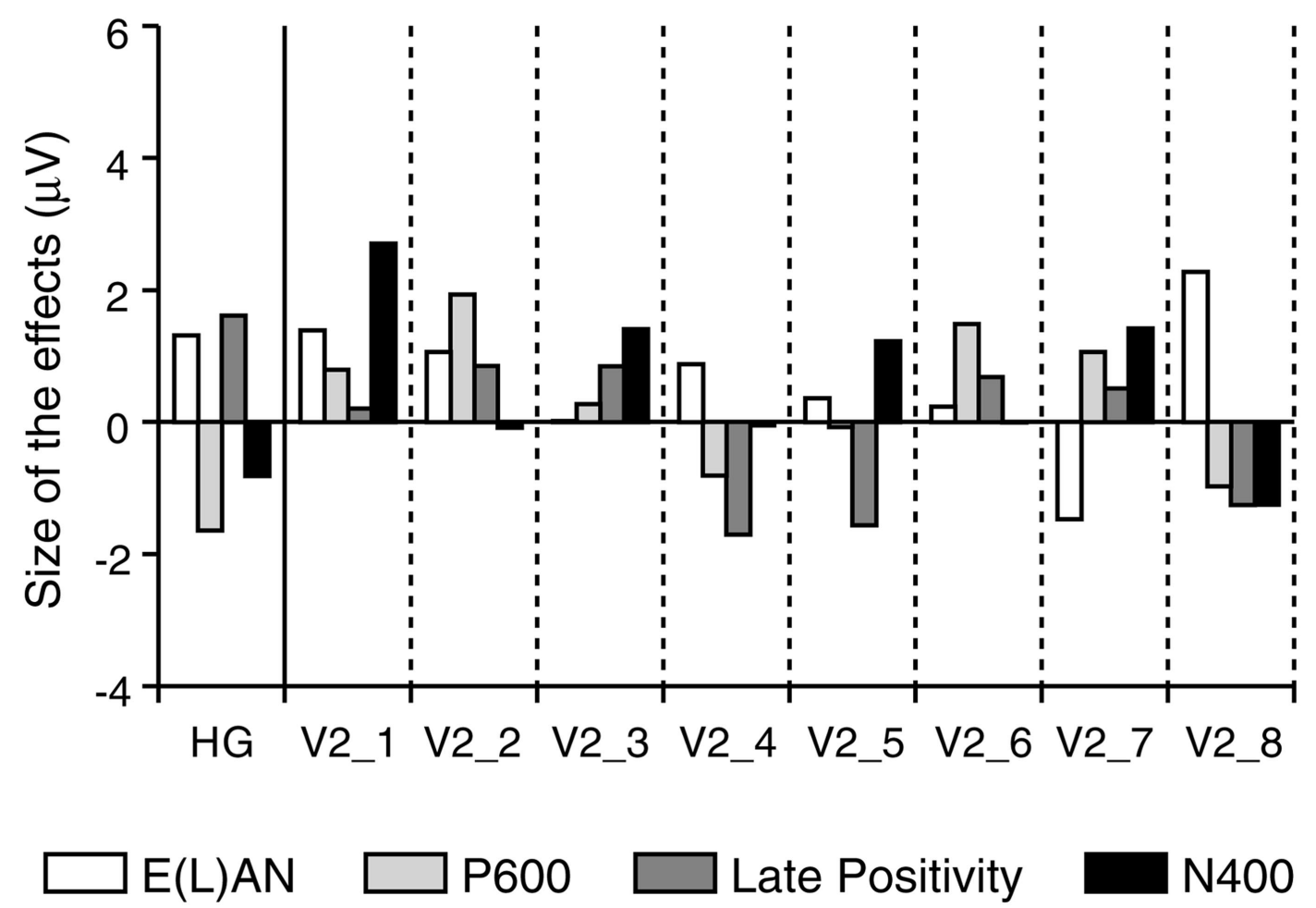

Figure 9. Graphical display of mean amplitude difference scores in $\mu V$ (incorrect-correct), calculated across selected electrode sites and regions (anterior vs. posterior), of the $E(L) A N$ (white bars), P600 (lighter gray bars), late positivity (darker gray bars), and N4OO (black bars) effects comparing each individual control subject (right) with HG (left) in the visual long modality. Individual control subject data is labelled as V2 (visual long) plus a numeral (subject number).

ERPs-controls. The waveforms for syntactic and semantic violation conditions are displayed in Figure 8. Individual subject data displaying all three components can be seen in Figure 9. As in the visual short SOA condition, approximately $8 \%$ of the trials were rejected across all conditions due to eye blinks, horizontal eye movement, or amplifier blocking. A fronto-central N1/P2 complex as well as a posterior $\mathrm{P} 1 / \mathrm{N} 1$ can be seen in the waveform. These early components were not followed by an early anterior negativity, while the centroparietal P600 (500-800 ms) as well as the late positivity was clearly visible. Similarly, there is a succession of early sensory components followed by an attenuated N400 component between 300 and $500 \mathrm{~ms}$ at centro-parietal sites. Quantification of the ERP data followed the same protocol as the analyses for the short visual SOA condition.
The repeated measures ANOVA for the early anterior negativity did not reveal a significant main effect of Condition, $F(1,7)=2.30, p>.173$, nor a significant Condition $\times$ Electrode site interaction, $F=0.65$. The statistical analysis for the P600 revealed a significant main effect of Condition, $F(1,7)=17.04, p<.004$, but no other main effect or interaction, $F<1$. The ANOVA for the late positivity revealed a main effect of Condition, $F(1,7)=6.89, p<.034$, but no other significant main effect or interaction, all $F<1$. The analyses of the N400 in the semantic condition resulted in a significant main effect of Condition, $F(1,7)=6.93, p<.033$, but no other significant main effect or interaction, all $F<1$. These results confirm a $\mathrm{P} 600$, a late positivity, and an N400, as have previously been described for the visual modality in the literature. 
PHONOLOGICAL STM IN SENTENCE PROCESSING

Table 4. Summary of the main ERP results in the syntactic and semantic conditions comparing controls and $H G$ across all modalities

\begin{tabular}{|c|c|c|c|c|}
\hline \multirow[b]{2}{*}{ ERP effects } & \multicolumn{3}{|c|}{ Syntactic condition } & \multirow{2}{*}{$\begin{array}{c}\text { Semantic condition } \\
\text { N400 } \\
(300-550 \mathrm{~ms})\end{array}$} \\
\hline & $\begin{array}{c}E(L) A N \\
(100-300 \mathrm{~ms})\end{array}$ & $\begin{array}{c}P 600 \\
(500-800 \mathrm{~ms})\end{array}$ & $\begin{array}{l}\text { Late positivity } \\
(900-1300 \mathrm{~ms})\end{array}$ & \\
\hline \multicolumn{5}{|l|}{ Controls } \\
\hline Auditory & + & + & + & + \\
\hline Visual short SOA & + & + & + & + \\
\hline Visual long SOA & - & + & + & + \\
\hline \multicolumn{5}{|l|}{$H G$} \\
\hline Auditory & + & + & - & + \\
\hline Visual short SOA & + & $--^{a}$ & + & + \\
\hline Visual long SOA & - & $--^{a}$ & + & + \\
\hline
\end{tabular}

Note: Dashes marked ${ }^{a}$ indicate HG's deficit in the syntactic condition.

ERP results-HG. Figure 8 compares the waveforms for both the syntactic and semantic violations with correct sentence types. While early sensory components such as the N1/P2 complex show a sharp and large amplitude at frontal electrode sites, the posterior P1/N1 complex was less enhanced. Furthermore, no early anterior negativity was visible. This effect was comparable to the normal controls (see confidence interval). Similar to the visual short SOA condition, there was a negative effect at posterior sites that started at around $300 \mathrm{~ms}$ and extended into the time window of the P600 in the controls $(500-800 \mathrm{~ms})$. Again, this negativity was followed by a late positivity at parietal/occipital sites between 900 to $1300 \mathrm{~ms}$. While the part of the negativity that lay within the latency range of the P600 was not within the confidence interval for the P600 of the controls, the difference score for the late positivity was within the confidence interval of the controls. There was also a biphasic pattern of an N400 followed by a positivity. The mean latency of the N400 was between 300 to $550 \mathrm{~ms}$, which is comparable to the controls. The distribution of the effect was frontoparietal; however, the activity appeared stronger at fronto-central than temporo-parietal sites. Nevertheless, the mean difference score for the N400 lay within the confidence interval of the controls.

\section{DISCUSSION}

The goal of the current study was to investigate syntactic and semantic sentence comprehension in correlation with pSTM capacities in a chronic aphasic patient who had suffered from a small frontal and a larger parieto-temporal left hemisphere lesion. Utilising ERPs, we set out to monitor the time course of syntactic and semantic sentence processing in this patient. We measured the on-line brain activity of three components (early anterior negativity, P600, and N400) that have been correlated with language processing in previous auditory (Friederici et al., 1993, 1999) and visual sentence comprehension experiments (e.g., Gunter et al., 1999) in normal and patient populations (Friederici et al., 1998, 1999; Swaab et al., 1995, 1997). By systematically varying the modality and SOA we attempted to document whether pSTM capacity differentially influences syntactic or semantic language processing as a function of speed of input and modality (auditory or visual). An attenuation and/or latency shift of a language-related component should help to specify the role of lesion site(s) on resulting functional deficits. The task was a sentence correctness task with phrase structure violations (syntactic condition) and selectional restriction violations (semantic condition). The main findings of normal controls and $\mathrm{HG}$ are summarised in Table 4 . The results 
of normal controls and HG will be discussed in turn.

\section{Age-matched controls}

The major findings for the controls can be described as follows: behavioural sentence judgment did not vary as a function of SOA and modality. Subjects rated all sentence types in the correct, syntactically incorrect, and semantically incorrect conditions with high accuracy. ERP measures reflected the expected pattern.

\section{Semantic processes}

Selectional restriction violations in the semantic condition resulted in a temporo-parietal N400 in both the auditory and the short visual modality. However, while statistically significant, the N400 amplitude was smaller in both visual SOA conditions. As has been reported previously, the amplitude of the N400 decreases as a function of age (Gunter et al., 1992). Since the mean age of the controls was 48 years, the current data are in line with this interpretation. Overall, the results are similar to the ones reported in previous semantic ERP experiments (e.g., Kutas \& Hillyard, 1983; Van Petten \& Kutas, 1991), indicating that the N400 reflects the integration of semantic information into a sentence context.

\section{Syntactic processes}

In the auditory and the visual short SOA modalities, subjects displayed a bilateral early anterior negativity followed by a centro-parietal positivity elicited by word category violations. The distribution of the early anterior negativity differed slightly in the two modalities while the latency was comparable. In the auditory modality the early negative effect was most prominent at lateral frontal and anterior sites (F7, F8, ATL, ATR). In the visual short SOA the effect was most visible at F3, F4, BL, BR. These results confirm previous evidence that reported slight distributional differences of the early negativity in the auditory (Friederici, 1995; Hahne \& Friederici, 1999) and the visual modality (Gunter et al., 1999; Neville et al., 1991). The fact that the early anterior negativity was found in both the auditory and visual modality (short SOA condition) supports the idea that the early anterior negativity is a modalityindependent component (see Gunter et al., 1999). Furthermore, if the assumption holds that the early anterior negativity is dependent on fast input, results from the auditory and visual short SOA modality support the notion that fast first-pass parsing processes are followed by slower second-pass parsing processes in the syntactic condition (Friederici, 1995).

Results from the visual long SOA condition support the notion that the early anterior negativity and its underlying processes are dependent on fast input. $^{2}$ There was no early anterior negativity, but a late centro-parietal positivity elicited in the syntactic condition. As argued in earlier work (Friederici et al., 1998), if initial fast processes are sensitive to input parameters such as changes in temporal order, the slowing down of the access of initial syntactic information should render the process inefficient.

Last, the P300 oddball data in both the auditory and the visual condition displayed the expected pattern in the control group. While the mean amplitude of the P300 effect varied slightly across subjects and conditions (see Figure 3), the data indicate that subjects followed task instructions attentively. Furthermore, the distribution of the P300 effect was typical in the auditory condition (parietal), while more widely distributed in the visual condition. This distribution has been observed before in normal (Friedman \& Simpson, 1994) and patient populations (Mecklinger et al., 1998). In particular, the more frontal distribution of the P300 effect has been interpreted as a reflection of memory update processes (Friedman \& Simpson, 1994). Given the

\footnotetext{
${ }^{2}$ Further evidence supporting the "automaticity" of the early anterior negativity comes from manipulations of proportion and instruction (Hahne \& Friederici, 1999, 2002), load (Vos, Gunter, Schriefers, \& Friederici, 2001), and proficiency (Hahne \& Friederici, 2001).
} 
age range of the control group (mean age 48), this conclusion is in line with the current results.

\section{Patient HG}

HG showed minor but process-specific differences in the on-line comprehension of sentences as revealed by the accuracy data. Accuracy measures indicate that HG had more problems judging syntactically incorrect than semantically incorrect or correct sentences across all modalities. Overall, sentence judgment for correct and semantically incorrect sentences was close to the judgment of controls across modalities.

While the overall ERP pattern in the auditory modality was comparable to that of the controls, the ERP pattern elicited during visual sentence comprehension supports the notion that the timing of the input critically influences late syntactic processes during reading in $\mathrm{HG}$.

\section{Semantic processes}

In the auditory modality, semantic processes similar to controls were reflected in an N400 but, unlike in controls, the N400 was followed by a late positivity. This pattern extended to the visual modalities. A small N400 effect was followed by a positivity in the short and long SOA condition. However, the amplitude difference between incorrect and correct trials in the long SOA condition was larger than in the short SOA condition.

\section{Syntactic processes}

With slowed-down input as realised in the visual modality, differences between aged-matched controls and HG become apparent. While the timing of the visual input did affect the early anterior negativity in the controls and $\mathrm{HG}$ in the long visual SOA condition, the SOA manipulation also influenced late syntactic processing in HG. The ERPs of HG in the syntactic domain displayed a late negativity followed by a delayed positivity in both visual SOA conditions. However, the onset of the late negativity was earlier in the long SOA than in the short SOA condition.
The combined auditory behavioral and ERP evidence of HG indicate that he appears to process syntactic sentence information similarly to controls as he showed an early anterior negativity and a late positivity (though the latter was more frontally distributed than the one seen in controls). In particular, the fact that $\mathrm{HG}$ shows an anterior negativity in the syntactic violation condition provides new evidence that this early negativity is indeed a reflection of early syntactic processing rather than a correlate of working memory. When processing semantic information in the auditory domain, lexical-semantic integration processes signalled by the N400 seem to be present, although somewhat attenuated. Thus, HG's pSTM deficit apparently does not affect either syntactic or semantic sentence judgment in the auditory domain, a result that is in line with previous behavioural evidence (e.g., Caplan \& Waters, 1990; Caramazza et al., 1981; Martin, 1987; Martin \& Feher, 1990).

When processing language visually, the ERP pattern in the syntactic violation condition clearly differs from controls, while the pattern for the semantic violation is comparable to controls. In the syntactic condition, HG displays a centroparietally distributed negativity around 500 and $800 \mathrm{~ms}$ followed by a late positivity between 900 and $1300 \mathrm{~ms}$. Both the negativity and the positivity have a somewhat later onset in the short than in the long SOA condition. These data suggest that the syntactic reanalysis or syntactic integration process (see Friederici, 2002; Kaan et al., 2000), associated with a centro-parietal P600, is manifested in a biphasic pattern of a late negativity and a delayed positivity in HG. What remains to be clarified is why the onset of this pattern is earlier in the long than the short SOA and why HG elicits a biphasic pattern in response to syntactic violations in the visual modality.

Taking the ERR results into consideration, HG's data may imply that syntactic processing in the visual modality is affected by his pSTM deficit as an altered ERP pattern is apparent (late negativity and positivity rather than a $\mathrm{P} 600$ ). However, temporal restriction in the visual domain (see results of the short SOA condition) also indicate 
that a computational deficit might contribute to the altered ERP pattern. HG's behavioural performance on the syntactic correctness judgment in the visual modality may allow to explain the latency onset differences in the ERP. Correctness scores in the short SOA condition were lower than in the long SOA condition. If our initial hypothesis was correct, upkeep of sentence information in the long SOA condition should have been more taxing than in the short SOA condition. This is not the case, as HG clearly scored higher in the long than the short SOA condition (see Table 2). Along this line, Martin and Feher (1990) argued that unlimited presentation of sentence information can facilitate the retention of information. Thus, HG's faster "syntactic" ERP response in the long visual SOA condition may reflect facilitated computation of syntactic information. This in turn may suggest that HG profits from a delayed presentation rate during syntactic correctness judgment in the visual domain.

So is the biphasic pattern of a late negativity and a delayed positivity a correlate of HG's pSTM deficit in the visual modality or not? According to linguistic theory, the mismatch in the phrase structure violations is primarily syntactic (word category error, verb instead of noun), however, it also bears semantic consequences as the preposition preceding the critical word (verb) requires a location term. Syntactically, a location term is a noun or an adverb, and the mismatch can, therefore, be detected during the initial first-pass parse on the basis of word category information. Semantically, however, the verb target also mismatches the expectation as it is not a location term and may, therefore, be detected as a mismatch on the basis of semantic aspects once the first-pass parse fails.

It is not unlikely that HG's performance is partly based on such semantic processes, which may reflect a strategic choice. If one assumes that the computation of syntactic information is affected by the word-by-word input in both visual conditions, such a process may come into play if word category identification is processed insufficiently. However, the fact remains that the biphasic pattern of a late negativity and a delayed positivity remains even when $\mathrm{HG}$ can process the information sufficiently in the long SOA condition. Interestingly, similar processes do not seem to be activated in controls, even when the input of information is slowed down. This result can be taken as evidence for a functional primacy of syntactic processes in normal comprehension even when early processes are not signalled by a difference between correct and incorrect sentences in the early anterior negativity.

Semantic errors, in contrast, appear to be detected earlier and in a time window comparable to controls (300-550 ms). Unlike in controls, however, this N400 is followed by a positivity in the P600 time domain. As for the auditory modality, it appears that the experienced difficulty of lexical integration is followed by additional processes that may aim to reanalyse the anomalous input.

A tentative interpretation of the observed behaviour, based on the specific lesion sites and the neuropsychological test scores, leaves open the possibility that HG's pSTM deficit interacts with a change and/or a temporal adjustment in language processing when a syntactic error is encountered. However, this only holds true for the visual modality, when sentences are presented in a wordby-word manner. Thus, the lack or the delay of a $\mathrm{P} 600$ as reflected in a late positivity following a late negativity in the syntactic condition may be evaluated as an interplay of a syntactic processing deficit with a STM deficit (e.g., Caplan \& Waters, 1999). If the delayed positivity can be compared to the $\mathrm{P} 600$ in normal controls, $\mathrm{HG}$ is able to initiate syntactic reanalysis or integration after a late detection of a syntactic error. On the other hand, the observed N400 effect in the semantic condition is comparable to the effect in controls. This N400, however, is followed by a positivity in the P600 time window, suggesting reanalysis processes after the experienced difficulty of lexical-semantic integration. This reanalysis is not evidenced in the ERP of controls when processing lexical-semantic anomalies due to selectional restriction violations.

Thus, the combined data from age-matched controls and HG, suggesting that the slowing down of the input from connected speech to a visual presentation with a $\mathrm{SOA}$ of $500 \mathrm{~ms}$ to one

\section{COGNITIVE NEUROPSYCHOLOGY, 2005, 22 (8)}


with a SOA of $1100 \mathrm{~ms}$ clearly affects syntactic, but to a lesser degree lexical-semantic, processes. In controls, slowing down only affects the ERP pattern in the long SOA condition, leading to an absence of the early anterior negativity but leaving the P600 unaffected. In HG, the slow-down of the input leads to an absence of the early anterior negativity in the syntactic condition, but a presence of a late centro-parietal negativity followed by a very late positivity instead. We have argued above that this pattern could reflect some late semantic processes resulting from the fact that the syntactic mismatch has semantic consequences. Taken together, the present findings indicate that syntactic structure building processes are more sensitive to general timing parameters than semantic processes.

On the basis of the observed P300 effects for HG in both the auditory and visual modality, which were not qualitatively different from controls, it is clear that ERP component attenuation in the linguistic tasks was not a function of a general processing deficit in $\mathrm{HG}$.

In conclusion, the current data provide further evidence for the view that normal processing and integration of "primary" syntactic information (e.g., word category information) during language comprehension critically depend upon a given temporal structure. As can be seen in $\mathrm{HG}$, the temporal adjustment of the time course of syntactic processing may correlate with pSTM capacities, but may not be the exclusive cause of the present results. The current single case ERP study, however, further suggests that clinical language classification based on an off-line test might not suffice to explain such correlations (see also Swinney, 1981).

Manuscript received 5 October 2000

Revised manuscript received 19 July 2004

Revised manuscript accepted 25 October 2004

PrEview proof published online 18 February 2005

\section{REFERENCES}

Baddeley, A. D. (2003). Working memory and language: An overview. Journal of Communication Disorders, 36, 189-208.
Berndt, R. S., \& Carmazza, A. (1980). A redefinition of the syndrome of Broca's aphasia: Implications for a neuropsychological model of language. Applied Psycholinguistics, 1, 225-278.

Caplan, D., Vanier, M., \& Baker, C. (1986). A case study of reproduction aphasia. II. Sentence comprehension. Cognitive Neuropsychology, 3, 129-146.

Caplan, D., \& Waters, G. S. (1990). Short-term memory and language comprehension: A critical review of the neuropsychological literature. In G. Vallar \& T. Shallice (Eds.), Neuropsychological impairments of short-term memory. Cambridge: Cambridge University Press.

Caplan, D., \& Waters, G. S. (1999). Working memory and sentence comprehension. Behavioral and Brain Sciences, 22, 77-126.

Caramazza, A., Basili, A., Koller, J. J., \& Berndt, R. S. (1981). An investigation of repetition and language processing in a case of conduction aphasia. Brain and Language, 14, 234-271.

Caramazza, A., Berndt, R. S., Basili, A. G., \& Koller, J. J. (1981). Syntactic processing deficits in aphasia. Cortex, 17, 333-348.

Caramazza, A., \& Zurif, E. B. (1976). Dissociation of algorithmic and heuristic processes in language comprehension: Evidence from aphasia. Brain and Language, 3, 572-582.

Caramazza, A., Zurif, E. B., \& Gardner, H. (1978). Sentence memory in aphasia. Neuropsychologia, 16, 661-669.

Daneman, M., \& Carpenter, P. (1980). Individual differences in working memory and reading. Journal of Verbal Learning and Verbal Behavior, 19, 450-466.

De Renzi, E., \& Vignolo, L. (1962). The token test: A sensitive test to detect receptive disturbances in aphasics. Brain, 85, 665-678.

Fiez, J. A. (1997). Phonology, semantics, and the role of the left inferior prefrontal cortex. Human Brain Mapping, 5, 79-83.

Fimm, B., \& Zimmermann, P. (1993). Testbatterie zur Aufmerksamkeitsprüfung (TAP), Version 1.02. Würselen, Germany: PSYTEST.

Frazier, L. (1987). Theories of sentence processing. In J. Garfield (Ed.), Modularity in knowledge representation and natural-language processing. Cambridge, MA: MIT Press.

Frazier, L., \& Fodor, J. D. (1978). The sausage machine: A new two-stage model of the parser. Cognition, 6, 291-325.

Friederici, A. D. (1985). Levels of processing and vocabulary types: Evidence from on-line comprehension in normals and agrammatics. Cognition, 19, 133-166. 
Friederici, A. D. (1988). Agrammatic comprehension: Picture of a computation mismatch. Aphasiology, 2, 279-282.

Friederici, A. D. (1995). The time course of syntactic activation during language processing: A model based on neuropsychological and neurophysiological data. Brain and Language, 50, 259-281.

Friederici, A. D. (1998). Diagnosis and reanalysis: Two processing aspects the brain may differentiate. In J. D. Fodor \& F. Ferreira (Eds.), Reanalysis in sentence processing (pp. 177-200). Dordrecht, The Netherlands: Kluwer.

Friederici, A. D. (2002). Towards a neural basis of auditory sentence processing. Trends in Cognitive Sciences, 6, 78-84.

Friederici, A. D., \& Frazier, L. (1992). Thematic analysis in agrammatic comprehension: Syntactic structures and task demands. Brain and Language, 42, 1-29.

Friederici, A. D., Hahne, A., \& Von Cramon, Y. D. (1998). First-pass versus second-pass parsing processes in a Wernicke's and a Broca's aphasic: Electrophysiological evidence for a double dissociation. Brain and Language, 62, 311-341.

Friederici, A. D., \& Kilborn, K. (1989). Temporal constraints on language processing: Syntactic priming in Broca's aphasia. Journal of Cognitive Neuroscience, 1, 262-272.

Friederici, A. D., Kotz, S. A., Werheid, K., Hein, G., \& Von Cramon D. Y. (2003a). Syntactic comprehension in Parkinson's disease: Investigating early automatic and late integrational processes using event-related brain potentials. Neuropsychology, 17, 133-142.

Friederici, A. D., Pfeifer, E., \& Hahne, A. (1993). Event-related brain potentials during natural speech processing: Effects of semantic, morphological and syntactic violations. Cognitive Brain Research, 1, 183-192.

Friederici, A. D., Rueschemeyer, S.-A., Hahne, A., \& Fiebach, C. F. (2003b). The role of left inferior frontal and superior temporal cortex in sentence processing: Localizing syntactic and semantic processes. Cerebral Cortex, 13, 170-177.

Friederici, A. D., Von Cramon, D. Y., \& Kotz, S. A. (1999). Language related brain potentials with cortical and subcortical left hemisphere lesions. Brain, 122, 1033-1047.

Friederici, A. D., Wang, Y., Herrmann, C. S., Maess, B., \& Oertel, U. (2000). Localization of early syntactic processes in frontal and temporal cortical areas. Human Brain Mapping, 11, 1-11.
Friedman, D., \& Simpson, G. V. (1994). ERP amplitude and scalp distribution to target and novel events: Effects of temporal order in young, middle aged and old adults. Cognitive Brain Research, 2, 49-63.

Geisser, S., \& Greenhouse, S. W. (1959). On methods in the analysis of profile data. Psychometrika, 24, 95-112.

Goodglass, H., \& Baker, E. (1976). Semantic field, naming, and auditory comprehension in aphasia. Brain and Language, 3, 359-374.

Gorrell, P. (1995). Syntax and parsing. Cambridge: Cambridge University Press.

Gunter, T. C., Friederici, A. D., \& Hahne, A. (1999). Brain responses during sentence reading: Visual input affects central processes. Neuroreport, 10, 3175-3178.

Gunter, T. C., Jackson, J. L., \& Mulder, G. (1992). An electrophysiological study of semantic processing in young and middle-aged academics. Psychophysiology, $29,38-54$.

Gunter, T. C., Jackson, J. L., \& Mulder, G. (1997). When syntax meets semantics. Psychophysiology, 34, 660-677.

Haarmann, H., \& Kolk, H. A. (1990). Computer model of the temporal course of agrammatic sentence understanding: The effects of variation in severity and sentence complexity. Cognitive Science, 15, 49-87.

Haarmann, H., \& Kolk, H. (1991). Syntactic priming in Broca's aphasics: Evidence for slow activation. Aphasiology, 5, 247-263.

Haarmann, H. J., \& Kolk, H. (1994). On-line sensitivity to subject-verb agreement violations in Broca's aphasics: The role of syntactic complexity and time. Brain and Language, 46, 493-516.

Hagoort, P. (1990). Tracking the time course of language understanding in aphasia. Doctoral dissertation, Catholic University of Nijmegen, The Netherlands.

Hagoort, P. (1993). Impairments of lexical-semantic processing in aphasia: Evidence from the processing of lexical ambiguities. Brain and Language, 45, 189-232.

Hagoort, P. (1997). Semantic priming in Broca's aphasics at a short SOA: No support for an automatic access deficit. Brain and Language, 56, 287-301.

Hagoort, P., Brown, C., \& Groothusen, J. (1993). The syntactic positive shift as an ERP-measure of syntactic processing. Language and Cognitive Processes, 8 , 439-483.

Hahne, A., \& Friederici, A. D. (1999). Electrophysiological evidence for two steps in syntactic analysis: Early automatic and late controlled processes. Journal of Cognitive Neuroscience, 11, 194-205. 
Hahne, A., \& Friederici, A. D. (2001). Processing a second language: Late learner's comprehension strategies as revealed by event-related brain potentials. Bilingualism: Language and Cognition, 4, 123-141.

Hahne, A., \& Friederici, A. D. (2002). Differential task effects on semantic and syntactic processes as revealed by ERPs. Cognitive Brain Research, 13, 339-356.

Hoffmann, M. (1996). Die Verarbeitung lokal ambiger Satzstrukturen bei Aphasie. Unpublished Master's thesis, Free University of Berlin, Germany.

Huber, W., Poeck, K., Weniger, D., \& Willmes, K. (1983). Aachener Aphasie Test (AAT). Göttingen, The Netherlands: Hofgrefe.

Just, M. A., \& Carpenter, P. (1992). A capacity theory of comprehension: Individual differences in working memory. Psychological Review, 99, 122-149.

Kaan, E., Harris, A., Gibson, E., \& Holcomb, P. J. (2000). The P600 as an index of syntactic integration difficulty. Language and Cognitive Processes, 15, 159-201.

Katz, W. F. (1988). An investigation of lexical ambiguity in Broca's aphasics using an auditory lexical priming technique. Neuropsychologia, 26, 747-752.

Kilborn, K. W., \& Friederici, A. D. (1994). Cognitive penetrability of syntactic priming in Broca's aphasia. Neuropsycholgy, 8, 83-90.

King, J., \& Kutas, M. (1995). Who did what and when? Using word- and clause-level ERPs to monitor working memory usage in reading. Journal of Cognitive Neuroscience, 7, 376-395.

Kluender, R., \& Kutas, M. (1993). Bridging the gap: Evidence from ERPs on the processing of unbound dependencies. Journal of Cognitive Neuroscience, 5, 196-214.

Kolk, H. H. J., \& Van Grunsven, M. J. F. (1985). Agrammatism as a variable phenomenon. Cognitive Neuropsychology, 2, 347-384.

Kotz, S. A., \& Von Cramon, D. Y. (1999). Is it timing after all? Behavioral and Brain Sciences, 22, 103-104.

Kutas, M., \& Hillyard, S. A. (1983). Event-related brain potentials to grammatical errors and semantic anomalies. Memory and Cognition, 11, 539-550.

Linebarger, M. C., Schwartz, M. F., \& Saffran, E. M. (1983). Sensitivity to grammatical structure in socalled agrammatic aphasics. Cognition, 13, 361-392.

Lukatela, K., Ocic, G., \& Shankweiler, D. (1991). Syntactic priming of inflected nouns in agrammatic aphasia. Poster presented at the Academy of Aphasia, Rome, Italy.

Martin, R. (1987). Articulatory and phonological deficits in short-term memory and their relation to syntactic processing. Brain and Language, 32, 159-192.
Martin, R., \& Feher, E. (1990). The consequences of reduced memory span for comprehension of semantic versus syntactic information. Brain and Language, $38,1-20$.

Martin, R., \& Romani, C. (1994). Verbal working memory and sentence processing: A multiple components view. Neuropsychology, 8, 506-523.

McCarthy, G., \& Wood, C. C. (1985). Scalp distribution of event-related potentials: An ambiguity associated with analysis of variance models. Electroencephalography and Clinical Neurophysiology, 62, 203-208.

McCarthy, R. A., \& Warrington, E. K. (1987a). The double dissociation of short-term memory for lists and sentences. Brain, 110, 1545-1564.

McCarthy, R. A., \& Warrington, E. K. (1987b). Understanding: A function of short-term memory? Brain, 110, 1565-1578.

Mecklinger, A., Von Cramon, Y., \& Matthes-von Cramon, G. (1998). Event-related potential evidence for a specific recognition memory deficit in patients with cerebral hypoxia. Brain, 121, 1919-1935.

Miceli, G., Mazzucchi, A., Menn, L., \& Goodglass, H. (1983). Contrasting cases of Italian agrammatic aphasia without comprehension disorder. Brain and Language, 19, 65-97.

Milberg, W., \& Blumstein, S. E. (1981). Lexical decision and aphasia: Evidence for semantic processing. Brain and Language, 14, 371-385.

Milberg, W., Blumstein, S. E., \& Dworetzky, B. (1987). Processing lexical ambiguities. Brain and Language, 31, 138-150.

Murray, D. J. (1968). Articulation and acoustic confusability in short-term memory. Journal of Experimental Psychology, 78, 679-684.

Neville, H.-J., Nicol, J. L., Barss, A., Forster, K. I., \& Garrett, M. F. (1991). Syntactically based sentence processing classes: Evidence from event-related brain potentials. Journal of Cognitive Neuroscience, 3, 155-170.

Osterhout, L., \& Holcomb, P. J. (1992). Event-related brain potentials elicited by syntactic anomaly. Journal of Memory and Language, 31, 785-804.

Ostrin, R. K., \& Tyler, L. K. (1993). Automatic access to lexical semantics in aphasia: Evidence from semantic and associative priming. Brain and Language, 45, 147-159.

Paulesu, E., Frith, C. D., \& Frackowiak, R. S. J. (1993). The neural correlates of the verbal component of working memory. Nature, 362, 342-344. 
Paulesu, E., Passingham, R. E., Frackowiak, R. J. S., \& Frith, C. D. (1996). Exploring the articulatory representations of verbal working memory with PET. NeuroImage, 3, S555.

Penke, M., Weyerts, H., Gross, M., Zander, E., Münte, T. F., \& Clahsen, A. (1997). How the brain processes complex words: An ERP-study of German verb inflections. Cognitive Brain Research, 6, 37-52.

Pfeifer, E., Novagk, R., \& Maeß, B. (1995). Software for EEG/ERP evaluation. Annual Report, Max-Planck-Institute of Cognitive Neuroscience, Leipzig, Germany.

Prather, P., Zurif, E., Stern, C., \& Rosen, T. J. (1992). Slowed lexical access in non-fluent aphasia. Brain and Language, 43, 336-348.

Saffran, E. M., \& Martin, O. S. M. (1975). Immediate memory for word lists and sentences in a patient with deficient auditory short-term memory. Brain and Language, 2, 420-433.

Shallice, T., \& Vallar, G. (1990). The impairment of auditory verbal short-term storage. In G. Vallar \& T. Shallice (Eds.), Neuropsychological impairments of short-term memory. Cambridge: Cambridge University Press.

Sharbrough, F. (1991). American Electroencephalographic Society guidelines for standard electrode position nomenclature. Journal of Clinical Neurophysiology, 8, 200-202.

Starr, A., \& Barrett, G. (1987). Disordered auditory short-term memory in man and event-related potentials. Brain, 110, 935-959.

Steinhauer, K. (1995). Hirnelektrische Korrelate sprachlicher Verarbeitungsprozesse beim Lesen lokal ambiger Relativsätze. Unpublished Master's thesis, Free University of Berlin, Germany.
Swaab, T. Y., Brown, C. M., \& Hagoort, P. (1995). Delayed integration of lexical ambiguities in Broca's aphasics: Evidence from event-related brain potentials. Brain and Language, 51, 159-161.

Swaab, T. Y., Brown, C. M., \& Hagoort, P. (1997). Spoken sentence comprehension in aphasia: Eventrelated potential evidence for a lexical integration deficit. Journal of Cognitive Neuroscience, 9, 39-66.

Swinney, D. (1981). Lexical processing during sentence comprehension: Effects of higher order constraints and implications for representation. In T. Meyers, J. Laver, \& J. Anderson (Eds.), The cognitive representation of speech. Amsterdam: North-Holland.

Vallar, G., Di Betta, A. M., \& Silveri, M. C. (1997). The phonological short-term store-rehearsal system: Patterns of impairment and neural correlates. Neuropsychologia, 35, 795-812.

Vallar, G., \& Papagno, C. (1986). Phonological shortterm store and the nature of the recency effect. Evidence from neuropsychology. Brain and Cognition, 5, 412-427.

Van Petten, C., \& Kutas, M. (1991). Influences of semantic and syntactic context on open- and closedclass words. Memory and Cognition, 19, 95-112.

Vorländer, T. (1986). Konzeption eines klinischen Kurzzeitgedächtnistets für hirngeschädigte Patienten. Unpublished Master's thesis, University of Trier, Germany.

Vos, S., Gunter, T. C., Schriefers, H., \& Friederici, A. D. (2001). Syntactic parsing and working memory: The effects of syntactic complexity, reading span and concurrent load. Language and Cognitive Processes, 16, 65-103.

Willmes, K., \& Poeck, K. (1993). To what extent can aphasic syndromes be localized? Brain, 116, 1527- 1540 . 